\title{
Omissão e colocação de clíticos por crianças bilingues Português-Francês ${ }^{1}$
}

\author{
Margarida Tomaz, Maria Lobo*, Ana Madeira*, Carla Soares-Jesel ${ }^{* *}$ \& Stéphanie Vaz* \\ *Universidade NOVA de Lisboa, CLUNL, ${ }^{* *}$ Université Paris Diderot, LLF
}

\begin{abstract}
:
This study investigates clitic omission and clitic placement in Portuguese-French bilingual children. Using two elicited production tasks, we show that the global pattern of development is very similar to the one found in monolingual acquisition: bilingual children are sensitive to the type of clitic (more omission in accusative contexts than in reflexive contexts), syntactic context (higher rates of pronoun production in islands than in simple sentences), and animacy (the rates of omission are always higher with inanimate antecedents). As for clitic placement, although the developmental path is similar to monolinguals, we find higher rates of proclisis in the bilinguals both in enclitic and in proclitic contexts, which may be caused by language transfer from French, although there are individual differences. We also show that a smaller group of Portuguese-French bilingual children who are speakers of the Brazilian Portuguese variety and exposed to European Portuguese in school context (and who are thus not only bilingual, but also bilectal) differ from the European PortugueseFrench bilinguals both in the rates of clitic production and in clitic placement patterns.
\end{abstract}

Keywords: language acquisition, bilingualism, heritage speakers, clitic omission, clitic placement, null object, Portuguese, French

Palavras-chave: aquisição da linguagem, bilinguismo, falantes de herança, omissão de clíticos, colocação de clíticos, objeto nulo, Português, Francês

\section{Introdução}

O presente trabalho tem como objetivo estudar a aquisição de pronomes clíticos por crianças bilingues falantes de francês e de uma variedade do português (europeia ou brasileira) expostas ao francês e à variedade europeia do português em contexto escolar, comparando o seu desempenho com o de crianças monolingues de Português Europeu (PE).

Embora o francês e as duas variedades do português tenham aspetos em comum, divergem quanto a uma série de propriedades sintáticas, em particular no que diz respeito à produção e colocação de pronomes complemento. Existem, pelo menos, dois aspetos em que PE e francês diferem: i) os contextos em que a omissão do clítico é permitida; e ii) a posição dos clíticos relativamente ao verbo matriz (ver secção 2). Já entre a variedade europeia e a brasileira estão descritas diferenças: i) nos contextos em que a omissão do pronome complemento é permitida; ii) na realização do pronome como pronome forte ou como clítico; iii) na colocação de clíticos.

Para explorar as diferenças e semelhanças entre a aquisição de clíticos em português por crianças monolingues e por crianças bilingues que estão também a adquirir o francês, aplicámos dois testes de produção induzida. $\mathrm{O}$ primeiro tem como objetivo investigar a produção de diferentes tipos de clíticos objeto (não reflexos e reflexos), em diferentes contextos sintáticos (em frases simples e em 'ilhas' sintáticas) e com

\footnotetext{
${ }^{1}$ Trabalho realizado no âmbito do projeto PESSOA 2017/19, 38033ZL (FCT, Ministério francês da Europa e dos Negócios Estrangeiros, Ministério francês da Educação Nacional, Ensino Superior e Investigação) da Bolsa de Doutoramento KRUse atribuída a Margarida Tomaz (PD/BD/113973/2015), e do Projeto Estratégico do CLUNL (UID/LIN/03213/2013) e parte do programa "Investissements d'Avenir", supervisionado pela Agência Nacional Francesa de Investigação, ANR-10-LABX-0083 (Labex EFL).
} 
diferentes traços de animacidade, e verificar se as crianças bilingues têm taxas de omissão/produção de clíticos em português semelhantes às dos monolingues. O segundo pretende investigar a aquisição da colocação de clíticos em orações com verbos simples, contemplando apenas o clítico se (comum a todas as variedades e aquele que tem taxas inferiores de omissão), em contextos de ênclise e em diferentes contextos de próclise, e verificar: i) se os padrões de desenvolvimento de crianças bilingues em português são semelhantes aos dos monolingues ou se são diferentes; ii) se há diferenças entre os grupos de bilingues que, para além do francês, falam apenas a variedade europeia e aqueles que estão expostos às duas variedades. A inclusão destes dois fenómenos permitir-nos-á caracterizar o desenvolvimento bilingue relativamente a dois fenómenos com diferentes propriedades gramaticais: a produção/omissão de clíticos, um fenómeno caracterizável como estando na interface sintaxe-discurso, e, portanto, mais vulnerável no desenvolvimento bilingue de acordo com algumas propostas (e.g. Müller \& Hulk, 2001); a colocação de clíticos, que, em contrapartida, não é caracterizável como um fenómeno de interface sintaxe-discurso, e que, à partida, deveria estar menos vulnerável no desenvolvimento bilingue. Para além do grupo PE/francês, maioritário, considerámos um pequeno grupo de crianças bilingues português/francês, expostas à variedade brasileira em casa e à variedade europeia em ambiente escolar, e procurámos determinar as diferenças no desenvolvimento da produção e colocação de clíticos entre estes dois grupos de crianças.

O artigo está organizado da seguinte forma: na secção 2., fazemos o enquadramento do fenómeno: apresentamos resumidamente as principais diferenças entre as variedades europeia e brasileira do português e o francês relativamente aos contextos de omissão de objeto (2.1.) e aos padrões de colocação de clíticos (2.2.), enquadramos o fenómeno nos estudos sobre o desenvolvimento bilingue (2.3.) e revemos os principais estudos já existentes sobre aquisição de produção de clíticos/pronomes e de colocação de clíticos no desenvolvimento bilingue e monolingue (2.4. e 2.5.); na secção 2.6., apresentamos as questões de investigação. Na secção 3., apresentamos o estudo de produção induzida de clíticos. Na secção 4, apresentamos o estudo de colocação de clíticos, e, na secção 5., discutimos os resultados.

\section{Enquadramento}

\subsection{Omissão do objeto em português e em francês}

Embora muitas línguas pareçam permitir algum tipo de omissão do objeto, existe variação interlinguística quanto às condições de licenciamento da omissão e plausivelmente quanto à natureza sintática do objeto elidido (Cummins \& Roberge, 2004, 2005; Pérez-Leroux, Pirvulescu \& Roberge, 2008). O pronome objeto no PE e no francês é sempre um pronome clítico, forma átona, sintaticamente e fonologicamente dependente de um hospedeiro verbal; ao passo que no PB o pronome objeto direto não reflexo em registos orais é geralmente realizado como um pronome forte (1). Em todas as línguas e variedades consideradas, o reflexo é um pronome clítico (2).

(1) a. A mãe lavou-a. (PE)

b. A mãe lavou ela. (PB)

c. La maman l'a lavée. (francês)

(2) a. A mãe lavou-se. (PE)

b. A mãe se lavou. (PB)

c. La maman s'est lavée. (francês)

Nas línguas que estamos a considerar, ambas as variedades do português são mais permissivas do que o francês quanto aos contextos em que a omissão do objeto é possível. O francês permite objetos nulos cognatos 
e objetos nulos arbitrários, mas apenas permite objetos nulos definidos recuperados discursivamente com determinados verbos, estando esta possibilidade lexicalmente condicionada. Veja-se os contrastes dados em Tuller (2000) (3).

(3) Le sac à dos de Luc pèse une tonne le vendredi soir. Ça contient tous ses livres et ses cahiers.

A mochila do Luc pesa uma tonelada na sexta à noite. Contém todos os seus livros e cadernos.

- *T'as déjà porté?

Já levaste?

- T’as déjà vu?

Já viste?

(Tuller 2000)

Para além disso, Cummins \& Roberge (2005) sugerem que este tipo de objeto nulo parece estar sujeito a algum tipo de restrição de animacidade, sendo mais facilmente omitidos objetos com o traço [- animado].

De acordo com as descrições existentes na literatura, ambas as variedades do português permitem omissão do objeto recuperado discursivamente ou contextualmente, mas diferem quanto aos contextos sintáticos em que a omissão é possível e quanto às restrições semânticas aos objetos elididos. Existe, contudo, alguma controvérsia quanto à descrição deste fenómeno, que mereceria uma investigação mais aprofundada. $\mathrm{Na}$ análise de Raposo (1989), o objeto nulo do PE é uma categoria vazia de tipo variável. Esta análise é fundamentada pelo facto de haver restrições à ocorrência de objeto nulo no interior de ilhas sintáticas:

(4) a. *O rapaz que trouxe [-] mesmo agora da pastelaria era teu afilhado.

b. *O pirata partiu para as Caraíbas depois de ter guardado [-] no cofre.

Contudo, mais recentemente, Raposo (2004) revê a sua análise e a sua descrição dos factos do PE e, identificando contextos em que pode haver omissão de objeto em ilhas sintáticas em PE, propõe que o objeto nulo do PE é um pronome nulo pro introduzido por um determinante nulo. Na verdade, continua a haver alguma controvérsia quanto aos contextos em que a omissão do objeto é legítima em PE e quanto ao estatuto gramatical da categoria vazia (Rinke, Flores \& Barbosa, 2018; Castro, Rothman \& Westergaard, 2017). Além disso, está por determinar até que ponto também em PE os traços de animacidade condicionam a omissão. Em Duarte \& Costa (2013) refere-se a animacidade do objeto como um fator relevante para a omissão no PE. No Português do Brasil (PB), tem-se descrito que a omissão do objeto pode ocorrer também no interior de ilhas sintáticas, mas está sujeita a restrições de animacidade e de especificidade, sendo possíveis apenas objetos nulos [- animados] ou [- específicos] (Bianchi \& Figueiredo-Silva, 1994). Esta categoria vazia, para alguns autores, corresponde a um pronome nulo pro (Galves, 1989; Bianchi \& Figueiredo-Silva, 1994; Rothman \& Iverson, 2013; e.o.); para outros, corresponde a uma estrutura de elipse (Cyrino, 2001; Cyrino \& Lopes, 2012). Rinke, Flores e Sopata (2019), que testaram a produção de diferentes tipos de objetos diretos por crianças bilingues PE/alemão e polaco/alemão nas suas línguas de herança (LH) - PE e polaco - , verificaram que os falantes de PE, quer os bilingues quer os monolingues, apresentam uma taxa de produção de clíticos mais elevada quando o antecedente tem o traço [+animado] do que quando este é [-animado].

Verificamos, assim, que o francês e duas variedades do português (PE, PB) admitem algum tipo de omissão do objeto, mas o francês é muito mais restritivo do que o português. Por outro lado, francês e PE distinguem-se do PB por realizarem os pronomes complemento como formas clíticas, ao passo que o PB pode realizar os pronomes complemento como formas fortes. 


\subsection{Colocação de clíticos em português e em francês}

A segunda propriedade sintática divergente entre português e francês é a posição do clítico relativamente ao verbo matriz. Como se sabe, os pronomes clíticos podem ocorrer numa posição adjacente à esquerda (próclise) ou à direita (ênclise) do verbo matriz. No PE, ao contrário das restantes línguas românicas, a colocação de clíticos é condicionada por fatores sintáticos. A ênclise é o padrão de colocação básico, não marcado, e a próclise ocorre em contextos sintáticos específicos. Como descrito em Duarte \& Matos (2000) e Brito, Duarte \& Matos (2003), a próclise ocorre na presença de desencadeadores de próclise, tais como orações com operadores de negação, sintagmas negativos em posição pré-verbal, orações com complementadores, sintagmas-wh, sujeitos quantificados em posição pré-verbal, elementos de foco antepostos e certos advérbios em posição pré-verbal. ${ }^{2}$

(5) a. A Maria emprestou-me o livro.

b. Ninguém se levantou do sofá.

No caso do francês, o pronome complemento clítico ocorre de forma generalizada em posição proclítica (6a). O único contexto em que não há próclise em francês é nos contextos de uso da forma imperativa afirmativa, em que o clítico ocorre em posição enclítica (6b):

(6) a. Pierre le lit. Pierre o lê

b. Lis-le!

Lê-o

Também no PB, a próclise é a posição preferencial (7):

(7) a. Ele me telefonou.

b. Ele não me telefonou.

Encontra-se, contudo, alguma taxa de ênclise, estando a variação condicionada por diferentes variáveis linguísticas e sociolinguísticas (Vieira, 2008).

\subsection{Desenvolvimento bilingue}

Os inúmeros estudos na área do bilinguismo consideram que, de forma geral, se deve distinguir os indivíduos bilingues de acordo com a idade de exposição a cada uma das línguas. Pode, assim, distinguir-se bilinguismo simultâneo e bilinguismo consecutivo ou sequencial. O primeiro carateriza-se pela aquisição de duas línguas, em simultâneo, como língua materna (L1), e implica que a criança seja exposta às duas línguas idealmente desde o nascimento e até sensivelmente aos 3 anos de idade (Unsworth, 2005; Meisel, 2008). Se o primeiro contacto da criança com uma segunda língua (L2) ocorrer depois dos 3 anos mas ainda numa idade precoce, considera-se que se trata de bilinguismo consecutivo ou sequencial (Unsworth, 2005; Meisel, 2008).

\footnotetext{
${ }^{2}$ O PE conta ainda com um terceiro padrão de colocação: a mesóclise. Este padrão de colocação, que se caracteriza pela inserção do clítico no meio da forma verbal, ocorre com as formas verbais do futuro e do condicional. No entanto, Duarte \& Matos (2000) afirmam que este é um "padrão regressivo que tende a ser substituído pela ênclise". Não considerámos incluir contextos de mesóclise para o nosso estudo porque a mesóclise parece já não estar a ser adquirida sem recurso à aprendizagem explícita e, além disso, é um fenómeno de aquisição tardia, como mostram os dados de Santos (2002): os adolescentes revelam dificuldades na colocação de clítico em contextos de mesóclise.
} 
Por vezes, identifica-se um grupo particular de bilingues, os chamados falantes de herança (FH). Os FH são considerados falantes bilingues, uma vez que adquirem duas (ou mais) línguas durante a infância (Flores, 2017; Flores et al., 2017). No entanto, nem todas as crianças bilingues são FH. O que carateriza os FH é o facto de estarem enquadrados numa situação sociolinguística particular. Por norma, são emigrantes de $2^{\mathrm{a}}$ e $3^{\mathrm{a}}$ geração que nasceram ou cresceram no seu país de acolhimento. Desde o nascimento, estas crianças estão expostas no seio familiar à língua falada pela família, e, ao mesmo tempo, estão a adquirir a língua maioritária do país onde residem, quer em meio escolar quer no contacto com a restante comunidade (Rothman, 2009). A aquisição de uma língua de herança (LH) tem sido amplamente discutida na literatura durante os últimos anos. Apesar de alguns autores defenderem que os FH não adquirem completamente a LH (Montrul, 2008), a posição dominante atualmente considera que os FH não são distintos de outros falantes bilingues, sugerindo que há diferenças suscetíveis de serem explicadas pela quantidade e qualidade do input, assim como por fatores relacionados com literacia e com a educação formal (Rothman, 2009; Kupisch \& Rothman, 2018).

A investigação mais recente tem mostrado que, na aquisição bilingue, os sistemas linguísticos se desenvolvem autonomamente e que os padrões de desenvolvimento dos bilingues são globalmente semelhantes aos dos monolingues (Meisel, 1989, 2004; Genesee, 1989; e.o.). Pode haver, contudo, alguma interação entre os sistemas das línguas em contacto (Paradis \& Genesee, 1996). Tem-se investigado o tipo de interação possível (aceleração, desaceleração ou transferência), a direcionalidade da interação e os fatores que a influenciam, bem como quais as áreas mais suscetíveis a que haja interferência. De acordo com Müller \& Hulk (2001), existem duas condições favoráveis à ocorrência de transferência entre línguas: áreas que envolvem fenómenos de interface sintaxe-discurso/pragmática e áreas em que há ambiguidade ou sobreposição estrutural dos dois sistemas. Sendo a produção de clíticos um fenómeno que envolve a interface sintaxe-discurso - requer a identificação dos contextos sintáticos em que um clítico não pode alternar com a construção de objeto nulo e requer também a determinação dos contextos em que o objeto nulo é legítimo -, espera-se que este seja um domínio vulnerável. A colocação de clíticos, pelo contrário, não é condicionada por fatores discursivos, pelo que não se prevê que haja interferência entre línguas.

Diferentes autores têm ainda questionado a influência da qualidade e quantidade de input sobre o desenvolvimento linguístico e o efeito da exposição a ensino formal, em particular no caso dos FH (Rinke \& Flores, 2014, e.o.). Para alguns autores, a menor exposição a cada uma das línguas pode levar a que haja um desenvolvimento mais lento na criança bilingue comparativamente à criança monolingue - o chamado "efeito bilingue" (Pirvulescu et al., 2014). Também a mudança na quantidade de input recebido em cada língua a partir da idade escolar tem mostrado ter efeitos na dominância linguística e condicionar a aquisição de fenómenos de desenvolvimento mais tardio (Thomas et al., 2014; Almeida \& Flores, 2017). O estudo de padrões de aquisição de clíticos por crianças FH em idade pré-escolar e escolar pode, assim, ajudar a identificar os fatores que condicionam o desenvolvimento linguístico neste tipo particular de população bilingue.

\subsection{Aquisição de produção de clíticos}

De acordo com estudos efetuados para diversas línguas, verifica-se que existe omissão de clíticos objeto em estádios iniciais da aquisição de uma língua. No entanto, esta omissão não é universal, uma vez que existem diferenças quanto às taxas de omissão e à idade em que este fenómeno deixa de ocorrer.

Uma das hipóteses explicativas para a omissão de clíticos em estádios iniciais de aquisição é a hipótese de Tsakali \& Wexler (2004) e Gavarrò, Torrens \& Wexler (2010), que propõe que a omissão de clíticos é esperada em línguas que manifestam concordância de particípio passado. Assim, em línguas como o catalão, italiano e francês, que manifestam concordância de particípio passado, são registadas taxas de omissão de clíticos até por volta dos 3 anos de idade. No caso de línguas como o espanhol, grego, servo-croata e romeno, que não manifestam concordância de particípio passado, é registada produção de clíticos desde cedo. Segundo 
os autores, a omissão em estádio iniciais de aquisição está diretamente relacionada com as restrições quanto ao número de traços que um elemento pode verificar. Esta restrição é designada por Restrição de Verificação Única (Unique Checking Constraint). Os autores explicam que existem diferenças entre línguas, pois existe um mecanismo de verificação duplo apenas nas línguas em que o objeto concorda diretamente com o particípio passado. Por conseguinte, será essa dupla verificação de traços que irá gerar a omissão de clíticos. Esta é uma restrição que está sujeita a maturação, ou seja, prevê-se que a omissão de clíticos termine por volta dos 3 anos de idade. Assim, e de acordo com esta hipótese, só existiria omissão de clíticos em línguas de concordância do objeto com o particípio passado.

No entanto, há trabalhos que mostram que, em francês, a realização de clíticos acusativos por crianças monolingues é mais tardia do que a realização de clíticos nominativos e que, depois dos três anos, a taxa de omissão dos primeiros ainda é significativa. Chillier et al. (2001), que testaram crianças com idades entre os $3 ; 5$ e os 6;5, obtiveram uma taxa de produção de clíticos acusativos de 68,5\% no grupo de crianças com idade média de 4 anos. A produção de clíticos aumenta para $88,1 \%$ no grupo de $4 ; 9$ anos (idade média). Tem-se sugerido que a aquisição mais tardia de clíticos acusativos em francês se explica por fatores relacionados com a complexidade da derivação sintática associada às configurações com clíticos. Para Jakubowicz et al. (1998), a dificuldade reside no facto de os clíticos acusativos corresponderem a elementos que apresentam um deficit categorial e que emergem numa posição não-canónica. Hamann \& Belletti (2006) sugerem que derivações com clíticos acusativos implicam operações sintáticas adicionais, não requeridas em derivações com outros pronomes.

Por outro lado, sendo o PE uma língua que não exibe concordância de particípio passado, seria esperado que as crianças deixassem de omitir clíticos desde cedo. No entanto, estudos sobre a aquisição de clíticos por crianças monolingues de PE (Costa \& Lobo, 2006; Costa, Lobo \& Silva, 2009; e Silva, 2008) mostram que existem elevadas taxas de omissão e que esta persiste até mais tarde, quando comparado o PE com línguas que também têm omissão de clíticos. Contudo, como referimos acima, o PE, ao contrário de outras línguas, dispõe da construção de objeto nulo (Raposo, 1986). Assim, em frases simples, não é claro se a omissão do clítico pela criança corresponde a uma estrutura-alvo de objeto nulo ou a problemas com essa estrutura sintática:

(8) - E o teu caderno?

- Levei Ø para a escola / Levei-o para a escola.

É, por isso, necessário considerar contextos em que o objeto nulo não seja legítimo. Os estudos citados anteriormente mostram que as crianças falantes de PE são mais permissivas do que os falantes adultos, uma vez que aceitam omissão de objeto em contextos em que esta não é permitida na gramática adulta (contextos de ilha e contextos reflexos). Os autores colocam então a hipótese de que a omissão de clíticos em PE, em estádios iniciais da aquisição, corresponde a uma sobregeneralização da construção de objeto nulo. Segundo Costa e Lobo, a natureza da omissão de clíticos em PE é diferente da natureza da omissão avançada para outras línguas. Nos estudos de Costa \& Lobo (2006), Costa \& Lobo (2007) e Carmona \& Silva (2007), ficou demonstrado que existe omissão em PE e que não existe evidência para favorecer a relação entre omissão e a concordância de particípio passado. Costa \& Lobo (2006) defendem que a omissão de clíticos em PE está relacionada com a complexidade do sistema. Fatores como a posição variável dos clíticos (ênclise e próclise) e a disponibilidade da construção de objeto nulo contribuem para essa complexidade.

O estudo de Costa \& Lobo (2007), que testou a produção de clíticos não-reflexos e reflexos (estes não alternam com a construção de objeto nulo), mostra que existem diferenças quanto à taxa de omissão destes dois tipos de clíticos: existe mais omissão em contextos não reflexos do que em contextos reflexos. Este é um dado que corrobora a hipótese avançada anteriormente pelos autores de que a omissão de clíticos em PE está 
diretamente relacionada com a complexidade do sistema. Se estivesse relacionada com a Restrição de Verificação Única, não deveria haver diferenças entre clíticos relativamente a taxas de omissão, visto que esta hipótese não prediz que existam assimetrias na produção de clíticos. Também no estudo de Silva (2009) foram encontradas assimetrias na produção dos diferentes tipos de clíticos testados (acusativos, dativos, reflexos e não-argumentais). A autora defende que "a melhor explicação para a omissão de clíticos para o caso específico do PE recai na hipótese colocada em termos de escolhas pós-sintáticas. Esta prediz uma taxa de omissão superior nos contextos em que os clíticos alternam com o objeto nulo." (Silva, 2009, p.540). Neste estudo foi registado um crescimento de produção de clíticos com consequente diminuição de objeto nulo à medida que a idade aumenta. No entanto, na faixa etária dos 6 anos a produção ainda não se aproxima da performance adulta.

Os dados de Costa \& Lobo (2010) vieram reforçar os dados obtidos anteriormente pelos autores. As crianças aceitam o objeto nulo em contextos reflexos e são capazes de os interpretar como os adultos. A omissão é defendida, mais uma vez, como sobregeneralização de objeto nulo, visto que as crianças conhecem a construção de objeto nulo, mas são mais permissivas do que os adultos, aceitando-a em contextos em que a gramática do adulto não a permite.

No estudo de Varlokosta et al. (2015), que testou a aquisição e produção de clíticos em 16 línguas, ficou demonstrado que, em termos gerais, as crianças aos 5 anos já são capazes de produzir elementos pronominais, o que revela que possuem conhecimento morfossintático ao nível da colocação, distribuição e forma alvo. Ao nível do conhecimento pragmático, as crianças testadas demonstraram um bom desempenho na medida em que selecionam a forma pronominal adequada ao discurso. No entanto, também foram encontradas algumas diferenças entre línguas, nomeadamente no que diz respeito às taxas de produção. Embora as formas pronominais sejam produzidas em todas as línguas, as taxas de produção não são iguais para todas as línguas. Os dados deste estudo acabam por corroborar dados dos estudos para o PE no que diz respeito à sobregeneralização da construção de objeto nulo. Mais uma vez, ficou demonstrado que as crianças falantes do PE têm preferência pelo objeto nulo e fazem uso desta forma mesmo em contextos em que na gramática adulta esta não é permitido. No entanto, não parece haver um problema ao nível da aquisição, uma vez que produzem clíticos de forma correta, embora numa taxa mais moderada. Trata-se sim de uma preferência por uma estrutura alternativa que está disponível na sua língua.

Também nos bilingues, a produção/omissão de clíticos e pronomes complemento é um fenómeno que tem sido estudado por vários autores. No estudo de Costa, Lobo \& Pratas (2013) foram testadas crianças bilingues caboverdiano/PE. Os resultados obtidos permitem confirmar os resultados anteriores, como em Varlokosta et al. (2015): aos 3 anos as crianças monolingues cabo-verdianas ainda revelam alguma omissão, mas na faixa etária dos 5 anos já praticamente não se regista omissão; as crianças monolingues do PE ainda generalizam a construção de objeto nulo na faixa etária dos 5 anos. Outra das principais conclusões deste estudo é o facto de as crianças bilingues mostrarem que existe interferência de um sistema no outro. No entanto, a interferência ocorreu apenas num sentido: as crianças bilingues fizeram uso de objetos nulos quando testadas em cabo-verdiano ${ }^{3}$ e não fizeram um uso extensivo de clíticos quando testadas em PE. Portanto, a forma nula surge como preferência, para os bilingues, face à forma clítica e não o contrário. Estes dados permitem confirmar assim a hipótese de Müller \& Hulk (2001) de que as áreas de interface são as que estão mais expostas a possíveis interferências na aquisição bilingue.

Nardelli $(2015)$ e Nardelli \& Lobo $(2017,2018)$ testaram a produção de clíticos por crianças bilingues PE/espanhol. Os dados obtidos revelam que as crianças bilingues omitem clíticos quer quando testadas em

\footnotetext{
${ }^{3}$ Em cabo-verdiano objetos nulos não são possíveis, contrariamente ao PE.
} 
espanhol quer quando testadas em PE. No entanto, as taxas de omissão são superiores quando testadas em PE. Os dados mostram ainda que as crianças bilingues omitem mais do que as crianças monolingues, confirmando assim o que está descrito na literatura na área da aquisição bilingue e monolingue dos clíticos. As crianças bilingues apresentam um desenvolvimento mais lento por terem um input mais ambíguo e mais reduzido em cada uma das línguas.

Paradis et al. (2003), num estudo sobre a aquisição de pronomes objeto por crianças bilingues francês/inglês, constataram que a omissão de pronomes complemento era mais elevada em francês do que em inglês e sugeriram que existia uma dificuldade associada especificamente às propriedades morfossintáticas dos pronomes clíticos do francês.

Pirvulescu et al. (2014) também investigaram a produção de pronomes complemento por crianças bilingues francês/inglês, comparando-a com a dos monolingues. Os autores verificam que os bilingues omitem mais em ambas as línguas do que os monolingues e atribuem isso à retenção de uma representação de objeto nulo por defeito. Vários tipos de objeto nulo são permitidos pela Gramática Universal, mas a determinação das propriedades sintáticas e lexicais que legitimam os diferentes tipos de objeto nulo é mais lenta nos bilingues devido a uma menor exposição ao input.

\subsection{Aquisição de colocação de clíticos}

No desenvolvimento monolingue, na maioria das línguas as crianças tendem a colocar os clíticos na sua posição correta. Em línguas em que a próclise é o padrão dominante, como o francês, ou em línguas em que a alternância entre ênclise e próclise está dependente da finitude do verbo, como o italiano, grego standard e espanhol, as crianças não apresentam erros de colocação, colocando sempre o clítico na posição esperada (Guasti, 1993/1994, para o italiano; Marinis, 2000, para o grego; Wexler, Gavarró \& Torrens, 2004, para o espanhol e catalão). Já para línguas em que o padrão dominante é a ênclise e em que a variação entre ênclise e próclise não é condicionada pela finitude, como o PE e o grego cipriota, existe uma tendência para generalização da ênclise e um desenvolvimento mais tardio da colocação de clíticos (Duarte \& Matos, 2000, para PE; Petinou \& Terzi, 2002, para o grego cipriota).

Costa, Fiéis \& Lobo (2015) estudaram a aquisição de colocação de clíticos por crianças monolingues de PE. Contrariamente ao que foi encontrado para outras línguas, em que as crianças colocam corretamente o clítico desde cedo, crianças falantes de PE com idades entre os 5 e os 7 apresentam alguns desvios. Estes desvios manifestam-se numa sobregeneralização da ênclise em contextos de próclise. No entanto, a situação inversa não se verifica. Os resultados obtidos pelos autores confirmam os dados de Duarte, Matos \& Faria (1995), que indicavam que na produção espontânea as crianças falantes de PE em processo de aquisição produziam clíticos com uma colocação que não estava de acordo com a gramática adulta. Costa, Fiéis \& Lobo (2015) mostram ainda que as taxas de erro de colocação de clítico não são iguais para todos os contextos de próclise, ou seja, os contextos de próclise são adquiridos de forma gradual de acordo com a seguinte escala (ordenada do contexto adquirido em primeiro lugar até ao último contexto a ser adquirido):

(9) Negação > Sujeitos negativos + Orações completivas > Advérbio já > Orações adverbiais > Sujeitos quantificados

Uma vez que a colocação dos clíticos em PE não está dependente da finitude das orações, como acontece para outras línguas, mas sim de propriedades lexicais específicas e contextos sintáticos específicos, os autores defendem que a aquisição da colocação de clíticos em PE se dá de forma mais lenta do que noutras línguas e de forma gradual.

No desenvolvimento bilingue, os estudos de Barbosa \& Flores (2011), Flores \& Barbosa (2014), Casa Nova (2015) e Flores, Barbosa \& Casa Nova (2016) mostram que os FH (português/alemão e 
português/francês) seguem um padrão de desenvolvimento de colocação de clíticos semelhante ao dos monolingues, embora o processo de aquisição seja mais tardio do que o dos monolingues. As autoras defendem que o facto de os FH estarem expostos a um input mais reduzido faz com que o processo de aquisição seja mais tardio e mais lento do que o dos monolingues.

Os FH começam por generalizar a ênclise e vão adquirindo, também de forma gradual como os monolingues, os contextos de próclise. Tal como os monolingues, também os FH fazem uso da ênclise em contextos de próclise, mas há diferenças entre os grupos português/francês e português/alemão. No grupo português/alemão não há produção de próclise em contextos de ênclise, mas há produção de próclise e ênclise em contextos de próclise. Este é um comportamento semelhante ao dos falantes monolingues mais novos do estudo de Costa, Fiéis \& Lobo (2015). Já o grupo-português/francês tem taxas mais altas de próclise em contextos de próclise e, ao contrário dos monolingues e do grupo português/alemão, tem taxas de produção de próclise em contextos de ênclise. Assim sendo, pode-se concluir que existe um processo de transferência linguística, tendo em conta que em francês a próclise é o padrão dominante. Esta transferência, segundo Casa Nova (2015), pode dever-se ao facto de a próclise ser uma estrutura comum aos dois sistemas, existindo assim um reforço do uso de uma propriedade também existente na língua dominante.

O fator idade revela ter um impacto significativo no desempenho dos falantes: os falantes mais novos comportam-se de maneira distinta dos falantes mais velhos. Os últimos apresentam taxas de acerto mais elevadas do que o primeiro grupo, em todos os contextos. Outro dos fatores analisados pelas autoras foi a exposição formal ao PE, que não revelou ser significativa para o desempenho dos falantes.

Um outro caso interessante é o da aquisição da colocação de clíticos no grego cipriota. O grego cipriota tem um padrão de colocação de clíticos com semelhanças com o PE, em que a ênclise é o padrão dominante, mas a língua de escolarização é o grego standard, que tem um padrão de colocação de clíticos semelhante ao do italiano e espanhol, ou seja, com próclise dominante. Os estudos de Leivada et al. (2010), Grohmann et al. (2012) e Agathocleous et al. (2014) mostram que as crianças cipriotas mais novas têm taxas mais altas de acerto na colocação de clíticos em grego cipriota do que as crianças mais velhas, possivelmente devido ao efeito da instrução e exposição formal ao grego standard.

\subsection{Questões de investigação}

Tendo em conta os trabalhos anteriores, identificámos as seguintes questões de investigação:

1. Será que o desenvolvimento do português das crianças bilingues português-francês relativamente à produção de clíticos é semelhante ao dos monolingues? Há taxas idênticas de omissão em bilingues e monolingues ou diferenças entre grupos (maior ou menor omissão nos bilingues)?

2. A animacidade, o tipo de clítico (reflexo vs. não-reflexo) e o contexto sintático (frase simples vs. ilha) exercem influência na produção de clíticos em todos os grupos?

3. Será que o desenvolvimento do português das crianças bilingues português-francês relativamente à colocação de clíticos é semelhante ao dos monolingues? Há taxas idênticas de generalização de ênclise em bilingues e monolingues ou existe maior taxa de próclise nos bilingues em português por influência do francês?

4. Há diferenças entre crianças falantes de diferentes variedades do português (PE vs. PB)? As crianças que têm o PB como L1 mantêm o padrão de colocação de clíticos do PB ou manifestam influência da exposição, ainda que reduzida, ao PE? 


\section{Teste de Produção de Clíticos}

\subsection{Metodologia}

\subsubsection{Participantes}

Participaram neste primeiro teste um total de 102 crianças, com as seguintes características:

\begin{tabular}{|c|c|c|c|c|c|c|c|c|c|}
\cline { 2 - 10 } \multicolumn{1}{c|}{} & \multicolumn{3}{c|}{ Monolingues PE } & \multicolumn{3}{c|}{ Bilingues PE/FR } & \multicolumn{3}{c|}{ Bilingues PB/FR } \\
\cline { 2 - 9 } & $\mathbf{N}^{\mathbf{o}}$ & $\begin{array}{c}\text { Intervalo } \\
\text { idades }\end{array}$ & $\begin{array}{c}\text { Média } \\
\text { idades }\end{array}$ & $\mathbf{N}^{\mathbf{0}}$ & $\begin{array}{c}\text { Intervalo } \\
\text { idades }\end{array}$ & $\begin{array}{c}\text { Média } \\
\text { idades }\end{array}$ & $\mathbf{N}^{\mathbf{0}}$ & $\begin{array}{c}\text { Intervalo } \\
\text { idades }\end{array}$ & $\begin{array}{c}\text { Média } \\
\text { idades }\end{array}$ \\
\hline Pré-escolar & 11 & $3-6$ anos & $\begin{array}{c}4,7 \\
(\mathrm{DP}=0,9)\end{array}$ & 9 & $4-5$ anos & $\begin{array}{c}4,5 \\
(\mathrm{DP}=0,6)\end{array}$ & 7 & $3-5$ & $\begin{array}{c}4,6 \\
(\mathrm{DP}=0,6)\end{array}$ \\
\hline Escolar & 51 & $6-10$ anos & $\begin{array}{c}7,4 \\
(\mathrm{DP}=1,1)\end{array}$ & 17 & $6-10$ anos & $\begin{array}{c}7,9 \\
(\mathrm{DP}=1,3)\end{array}$ & 7 & $6-8$ & $\begin{array}{c}6,8 \\
(\mathrm{DP}=0,8)\end{array}$ \\
\hline
\end{tabular}

Tabela 1 Participantes do teste de produção de clíticos ${ }^{4}$.

Todas as crianças bilingues são falantes de herança de português, de segunda geração, residentes em França. Estas crianças frequentam o ensino regular francês no Lyceé International Saint-Germain-en-Laye e na École Maternelle et Primaire Normandie-Niémen - Le Pecq. Duas vezes por semana, num total de 6 horas, frequentam aulas de português. A variedade falada pela professora nas aulas é o PE. Todas as crianças estão expostas ao português (variedade europeia ou brasileira) e ao francês em casa. ${ }^{5}$

As crianças monolingues residem na área metropolitana de Lisboa e frequentam a Escola Básica do Bairro da Covina (Santa Iria de Azoia, Loures).

\subsubsection{Procedimento}

Com o objetivo de verificar se as crianças bilingues omitem clíticos em português, aplicámos um teste de produção induzida, adaptado de Nardelli \& Lobo (2017). Uma vez que vários autores mostram que a animacidade do antecedente desempenha um papel importante aquando da retoma do mesmo em ambas as variedades do português (cf. Lopes \& Cyrino, 2005; Duarte \& Costa, 2013; Castro, Rothman \& Westergaard, 2017, entre outros), manipulámos a variável animacidade nos itens de teste que induziam a produção de clíticos não reflexos.

O teste continha 38 itens ( 4 de treino e 34 de teste) que induziam a produção de clíticos acusativos e reflexos em diferentes contextos sintáticos:

(10) a) clítico acusativo, frase simples, antecedente [+ animado] - 6 itens;

b) clítico acusativo, frase simples, antecedente [- animado] - 6 itens;

c) clítico acusativo, ilha, antecedente [+ animado] - 6 itens;

d) clítico acusativo, ilha, antecedente [- animado] - 6 itens;

e) clítico reflexo, frase simples - 10 itens.

\footnotetext{
${ }^{4} \mathrm{DP}=$ desvio padrão

${ }^{5}$ Foi distribuído um questionário sociolinguístico aos pais/encarregados de educação das crianças bilingues. Em trabalho futuro, serão cruzados os dados do questionário (em particular quanto às variáveis dominância linguística, tempo de exposição à língua e tempo de ensino formal) com os resultados obtidos nos testes de produção induzida de clíticos.
} 
Estes três contextos sintáticos permitem-nos verificar se as crianças fazem distinção entre os contextos em que a omissão é permitida em PE (clíticos acusativos em frases simples) e os contextos em que esta não é permitida na gramática adulta do PE (clíticos reflexos; clíticos acusativos em contexto de ilha).

Todos os participantes foram testados individualmente, as respostas foram anotadas numa folha de registo, gravadas em formato de áudio e posteriormente transcritas e codificadas num ficheiro Excel. Após a apresentação de uma imagem em computador, pedia-se ao participante que respondesse a uma questão ou que completasse uma frase.

Apresentamos, de seguida, imagens exemplificativas das condições deste teste.

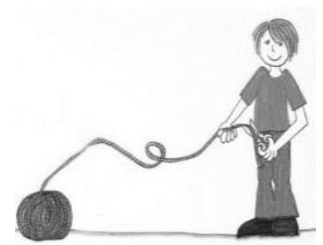

Figura 1 Exemplo da condição de clítico acusativo, frase simples, antecedente [-animado].

Investigador: Temos aqui um rapaz e um novelo de lã. $\mathrm{O}$ que é que o rapaz está a fazer ao novelo de lã?

Resposta esperada:

PE - Está a cortá-lo./Está a cortar [-].

PB - Está cortando ele. /Está cortando [-].

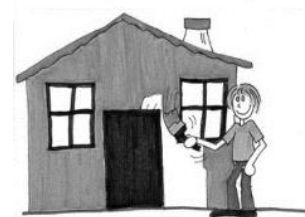

Figura 3 Exemplo da condição de clítico acusativo, ilha, antecedente [-animado].

Investigador: $\mathrm{O}$ homem pintou a casa e a casa ficou azul. Porque é que a casa ficou azul? A casa ficou azul porque o homem...

Resposta esperada:

PE - ... a pintou. | PB - ... pintou ela/ [-].

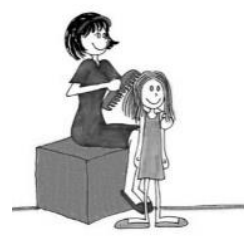

Figura 2 Exemplo da condição de clítico acusativo, frase simples, antecedente [+animado].

Investigador: Temos aqui uma mãe e uma filha. O que é que a mãe está a fazer à filha?

Resposta esperada:

PE - Está a penteá-la. /Está a pentear [-].

PB - Está penteando ela. /Está penteando [-].

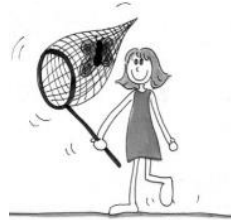

Figura 4 Exemplo da condição de clítico acusativo, ilha, antecedente [+animado].

Investigador: A menina apanhou a borboleta e a borboleta não pode voar. Porque é que a borboleta não pode voar? A borboleta não pode voar porque a menina....

Resposta esperada:

PE - ... a apanhou. | PB - ... apanhou ela.

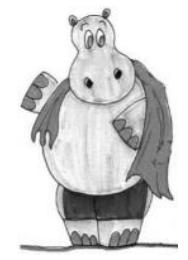

Figura 5 Exemplo da condição de clítico reflexo. Investigador: $\mathrm{O}$ hipopótamo saiu da água e pegou numa toalha. O que é que o hipopótamo está a fazer? Resposta esperada:

PE - Está a limpar-se (secar-se).

PB - Está se limpando. 
As respostas foram classificadas de acordo com as seguintes categorias: a) produção de clítico-alvo; b) produção de pronome forte; c) omissão; d) produção de DP; e) outra resposta, f) ausência de resposta.

\subsubsection{Análise estatística}

Para verificar se as diferenças encontradas são estatisticamente significativas recorremos ao teste nãoparamétrico de Wilcoxon no programa $R$. Para variáveis intrassujeitos usámos o paired samples Wilcoxon test e para as variáveis intersujeitos usámos o unpaired two-samples Wilcoxon test.

\subsection{Resultados}

Apresentamos de seguida os resultados obtidos por condição em cada um dos grupos.

Na tabela 2, podem observar-se os resultados obtidos para o contexto acusativo em frases simples:

\begin{tabular}{|c|c|c|c|c|c|c|}
\cline { 2 - 7 } \multicolumn{1}{c|}{} & \multicolumn{2}{c|}{ Monolingues PE } & \multicolumn{2}{c|}{ PE/FR } & \multicolumn{2}{c|}{ PB/FR } \\
\cline { 2 - 7 } \multicolumn{1}{c|}{} & Pré-escolar & Escolar & Pré-escolar & Escolar & Pré-escolar & Escolar \\
\hline clítico & $40,3 \%$ & $52,4 \%$ & $10,2 \%$ & $21,1 \%$ & $1,4 \%$ & $16,7 \%$ \\
\hline DP & $14,6 \%$ & $14,6 \%$ & $11,1 \%$ & $31,4 \%$ & $41,7 \%$ & $36,9 \%$ \\
\hline omissão & $28,5 \%$ & $22,3 \%$ & $64,8 \%$ & $39,2 \%$ & $36,1 \%$ & $27,4 \%$ \\
\hline outra & $16,7 \%$ & $10,1 \%$ & $13 \%$ & $8,3 \%$ & $19,4 \%$ & $15,5 \%$ \\
\hline pronome forte & - & $0,6 \%$ & - & - & $1,4 \%$ & $3,6 \%$ \\
\hline NR & - & - & $0,9 \%$ & - & - & - \\
\hline
\end{tabular}

Tabela 2 Resultados globais para o contexto acusativo em frases simples.

Como se pode observar na tabela 2, os grupos de bilingues têm taxas de omissão superiores às registadas para o grupo de monolingues. Um teste estatístico de Wilcoxon confirma que a diferença entre monolingues e bilingues é significativa (Monolingues PE vs PE/FR: $p<0.001$; Monolingues PE vs PB/FR: $p=0.02$ ). Se compararmos os diferentes grupos de bilingues, verificamos que quer a taxa de omissão $(p=0.001028)$ quer a taxa de produção de clíticos $(p=0.02685)$ são sempre superiores para o grupo PE/FR. Relativamente aos resultados do grupo $\mathrm{PB} / \mathrm{FR}$, é possível observar que a produção de clítico/pronome forte ocorre maioritariamente no grupo escolar e que apenas para este grupo é que há registo de produção de pronome forte (o valor do grupo escolar monolingue é residual). Todos os grupos têm um comportamento idêntico na medida em que a taxa de produção de clíticos é sempre superior no grupo Escolar e a taxa de omissão é sempre superior para o grupo Préescolar. No entanto, as diferenças entre as crianças de idade pré-escolar e escolar não revelam ser estatisticamente significativas para todos os grupos, como podemos observar na tabela:

\begin{tabular}{|c|c|c|c|c|c|c|}
\cline { 2 - 7 } \multicolumn{1}{c|}{} & \multicolumn{2}{c|}{ Monolingues PE } & \multicolumn{2}{c|}{ PE/FR } & \multicolumn{2}{c|}{ PB/FR } \\
\cline { 2 - 7 } \multicolumn{1}{c|}{} & omissão & clítico & omissão & clítico & omissão & clítico \\
\hline $\boldsymbol{p}$ & 0.46 & 0.1671 & $<\mathbf{0 . 0 0 1}$ & $<\mathbf{0 . 0 0 1}$ & 0.4989 & $\mathbf{0 . 0 1 3 4 2}$ \\
\hline
\end{tabular}

Tabela 3 Valores de $p$ para a variável nível de escolaridade.

Nos dados da tabela 3, podemos observar a relevância da variável nível de escolaridade em cada um dos grupos de participantes. Existem diferenças estatisticamente significativas no grupo de bilingues PE/FR, quer na taxa de produção de clíticos quer na taxa de omissão. No grupo de bilingues PB/FR existe diferença

\footnotetext{
${ }^{6} 2.9 \%$ correspondem à produção de clítico dativo.
} 
estatisticamente significativa só na taxa de produção de clíticos. Relativamente ao grupo de monolingues PE não existem diferenças estatisticamente significativas.

Vejamos agora os resultados obtidos para o contexto acusativo em ilha:

\begin{tabular}{|c|c|c|c|c|c|c|}
\cline { 2 - 7 } \multicolumn{1}{c|}{} & \multicolumn{2}{c|}{ Monolingues PE } & \multicolumn{2}{c|}{ PE/FR } & \multicolumn{2}{c|}{ PB/FR } \\
\cline { 2 - 7 } \multicolumn{1}{c|}{} & Pré-escolar & Escolar & Pré-escolar & Escolar & Pré-escolar & Escolar \\
\hline clítico & $39,6 \%$ & $63,1 \% 7$ & $13 \%$ & $38,7 \%$ & - & $17,9 \%$ \\
\hline DP & $6,9 \%$ & $8,5 \%$ & $16,7 \%$ & $26 \%$ & $13,9 \%$ & $40,5 \%$ \\
\hline omissão & $45,8 \%$ & $23,4 \%$ & $55,6 \%$ & $30,4 \%$ & $52,8 \%$ & $21,4 \%$ \\
\hline outra & $7,6 \%$ & $3,8 \%$ & $14,8 \%$ & $4,9 \%$ & $20,8 \%$ & $6 \%$ \\
\hline pronome forte & - & $1,1 \%$ & - & - & $12,5 \%$ & $14,3 \%$ \\
\hline
\end{tabular}

Tabela 4 Resultados globais para o contexto acusativo em ilhas.

Relativamente aos resultados obtidos para o contexto acusativo em ilha, tal como no contexto acusativo em frase simples, os grupos de bilingues têm uma taxa de omissão superior à taxa de omissão registada no grupo de monolingues ${ }^{8}$ (Monolingues PE vs PE/FR: $p<0.001$; Monolingues vs PB/FR: $p=0.0212$ ). Se compararmos os dois grupos de bilingues, verificamos que a taxa de produção de clíticos é sempre superior para o grupo PE/FR $(p<0.001)$. Relativamente ao tipo de pronome produzido nos grupos bilingues, podemos observar que o grupo PE/FR produz mais clíticos do que o grupo PB/FR e que os pronomes fortes são produzidos quase exclusivamente pelo grupo PB/FR. Tal como na condição anterior, também nesta condição existe um efeito do fator idade: em todos os grupos, a taxa de produção de clíticos é sempre superior no grupo Escolar e a taxa de omissão é sempre superior para o grupo Pré-escolar. Na tabela podemos verificar que as diferenças encontradas são estatisticamente significativas em todos os grupos, quer na taxa de produção de clíticos quer nas taxas de omissão:

\begin{tabular}{|c|c|c|c|c|c|c|}
\cline { 2 - 7 } \multicolumn{1}{c|}{} & \multicolumn{2}{c|}{ Monolingues PE } & \multicolumn{2}{c|}{ PE/FR } & \multicolumn{2}{c|}{ PB/FR } \\
\cline { 2 - 7 } \multicolumn{1}{c|}{} & omissão & clítico & omissão & clítico & omissão & clítico \\
\hline $\boldsymbol{p}$ & $<0.001$ & 0.001954 & 0.00139 & $<0.001$ & $<0.001$ & $<0.001$ \\
\hline
\end{tabular}

Tabela 5 Valores de $p$ para a variável nível de escolaridade.

Na tabela 6, podem ser observados os resultados obtidos para a condição de clíticos reflexos:

\begin{tabular}{|c|c|c|c|c|c|c|}
\cline { 2 - 7 } \multicolumn{1}{c|}{} & \multicolumn{2}{c|}{ Monolingues PE } & \multicolumn{2}{c|}{ PE/FR } & \multicolumn{2}{c|}{ PB/FR } \\
\cline { 2 - 7 } \multicolumn{1}{c|}{} & Pré-escolar & Escolar & Pré-escolar & Escolar & Pré-escolar & Escolar \\
\hline clítico & $50,8 \%$ & $76,5 \%{ }^{9}$ & $41,1 \%$ & $70 \%$ & $28,3 \%$ & $48,6 \%$ \\
\hline DP & - & - & $1,1 \%$ & - & - & - \\
\hline
\end{tabular}

\footnotetext{
${ }^{7} 12,3 \%$ correspondem à produção de clítico dativo.

${ }^{8}$ Com exceção do grupo PB/FR escolar, que produziu uma taxa muito elevada de DP.

${ }^{9} 0,2 \%$ correspondem à produção de clítico dativo.
} 


\begin{tabular}{|c|c|c|c|c|c|c|}
\hline omissão & $18,3 \%$ & $5 \%$ & $24,4 \%$ & $8,8 \%$ & $25 \%$ & $12,9 \%$ \\
\hline outra & $30,8 \%$ & $18,5 \%$ & $31,1 \%$ & $21,2 \%$ & $45 \%$ & $35,7 \%$ \\
\hline pronome forte & - & - & - & - & $1,7 \%$ & $2,9 \%$ \\
\hline NR & - & - & $2,2 \%$ & - & - & - \\
\hline
\end{tabular}

Tabela 6 Resultados globais para o contexto reflexo.

Tal como nos contextos anteriormente analisados, também para este contexto podemos verificar que os grupos de bilingues têm uma taxa de omissão superior à taxa de omissão registada para o grupo de monolingues (monolingues PE vs PE/FR: $p<0.001$; monolingues vs PB/FR: $p<0.001$ ). Comparando os dois grupos de bilingues, contrariamente aos resultados obtidos nas condições anteriores, o grupo PB/FR regista uma taxa de omissão superior à do grupo PE/FR, embora sem diferença estatisticamente significativa ( $p=$ 0,2159). Relativamente à taxa de produção de clíticos, o grupo PE/FR tem registo de uma taxa superior à do grupo PB/FR $(p<0.001)$. Tal como nas condições anteriores, também aqui se verifica um efeito do fator idade: a taxa de produção de clíticos é sempre superior no grupo Escolar e a taxa de omissão é sempre superior para o grupo Pré-escolar. No entanto, as diferenças não revelam ser estatisticamente significativas para todos os grupos, como podemos observar na tabela:

\begin{tabular}{|c|c|c|c|c|c|c|}
\cline { 2 - 7 } \multicolumn{1}{c|}{} & \multicolumn{2}{c|}{ Monolingues PE } & \multicolumn{2}{c|}{ PE/FR } & \multicolumn{2}{c|}{ PB/FR } \\
\cline { 2 - 7 } \multicolumn{1}{c|}{} & omissão & clítico & omissão & clítico & omissão & clítico \\
\hline$p$ & 0.1134 & $<\mathbf{0 . 0 0 1}$ & $\mathbf{0 . 0 2 8 9 2}$ & $<\mathbf{0 . 0 0 1}$ & 0.1169 & $\mathbf{0 . 0 2 8 9 2}$ \\
\hline
\end{tabular}

Tabela 7 Valores de $p$ para a variável nível de escolaridade.

Observando os dados da tabela 7, podemos concluir que existem diferenças estatisticamente significativas no grupo de bilingues PE/FR, quer na taxa de produção de clíticos quer na taxa de omissão. No grupo de bilingues PB/FR e no grupo de monolingues PE existe diferença estatisticamente significativa só na taxa de produção de clíticos.

Comparando os resultados obtidos nas três condições, verificamos que existe mais omissão nos contextos acusativos do que no contexto reflexo, em todos os grupos (monolingues: $p<0.001$; PE/FR: $p<$ 0.001; PB/FR: $p=0,024)$, e maior produção de clíticos no contexto reflexo do que nos contextos acusativos em todos os grupos (cf. Tabela 8) (monolingues: $p=0,001571$; PE/FR: $p<0.001$; PB/FR: $p<0.001$ ). As diferenças entre produção de clíticos acusativos e reflexos é particularmente notória nos grupos de bilingues.

\begin{tabular}{|c|c|c|c|c|c|c|}
\cline { 2 - 7 } \multicolumn{1}{c|}{} & \multicolumn{2}{c|}{ Monolingues PE } & \multicolumn{2}{c|}{ PE/FR } & \multicolumn{2}{c|}{ PB/FR } \\
\cline { 2 - 7 } \multicolumn{1}{c|}{} & Pré-escolar & Escolar & Pré-escolar & Escolar & Pré-escolar & Escolar \\
\hline Acus. f. simples & $40,3 \%$ & $52,4 \%$ & $10,2 \%$ & $21,1 \%$ & $1,4 \%$ & $16,7 \%$ \\
\hline Acus. ilha & $39,6 \%$ & $63,1 \%$ & $13 \%$ & $38,7 \%$ & - & $17,9 \%$ \\
\hline Reflexo & $50,8 \%$ & $76,5 \%$ & $41,1 \%$ & $70 \%$ & $28,3 \%$ & $48,6 \%$ \\
\hline
\end{tabular}

Tabela 8 Taxas de produção de clíticos nos três contextos.

Como referido anteriormente, a animacidade do antecedente desempenha um papel importante aquando da retoma do mesmo em ambas as variedades do português (cf. Lopes \& Cyrino, 2005; Duarte \& Costa, 2013; Castro, Rothman \& Westergaard, 2017, entre outros). Segundo esta restrição de animacidade, antecedentes [animados] são geralmente retomados por objetos nulos e antecedentes [+animados] são geralmente retomados por pronomes. 
Nas tabelas 9 e 10 podemos observar os resultados obtidos quando considerada a variável animacidade do antecedente, considerando apenas as respostas com clítico/pronome e omissão:

\begin{tabular}{|c|c|c|c|c|c|c|c|}
\hline & & \multirow{2}{*}{\multicolumn{2}{|c|}{ Monolingues PE }} & \multirow{2}{*}{\multicolumn{2}{|c|}{ Bilingues PE/FR }} & & \\
\hline & & & & & & \multicolumn{2}{|c|}{ Bilingues PB/FR } \\
\hline & & Pré-escolar & Escolar & Pré-escolar & Escolar & Pré-escolar & Escolar \\
\hline \multirow{3}{*}{ [-animado] } & clítico & $55,8 \%$ & $64,3 \%^{10}$ & $9,3 \%$ & $30,6 \%$ & - & $28,6 \%$ \\
\hline & omissão & $44,2 \%$ & $35,3 \%$ & $90,7 \%$ & $69,4 \%$ & $100 \%$ & $71,4 \%$ \\
\hline & pronome forte & - & $0,4 \%$ & - & - & - & - \\
\hline \multirow{3}{*}{ [+animado] } & clítico & $70,7 \%$ & $76,1 \%^{11}$ & $18,4 \%$ & $39,3 \%$ & $7,1 \%$ & $42,1 \%$ \\
\hline & omissão & $29,3 \%$ & $22,5 \%$ & $81,6 \%$ & $60,7 \%$ & $85,7 \%$ & $42,1 \%$ \\
\hline & pronome forte & - & $1,4 \%$ & - & - & $7,1 \%$ & $15,8 \%$ \\
\hline
\end{tabular}

Tabela 9 Resultados da variável animacidade obtidos para o contexto acusativo em frases simples.

\begin{tabular}{|c|c|c|c|c|c|c|c|}
\hline & \multicolumn{2}{|c|}{ Monolingues PE } & \multicolumn{2}{|c|}{ Bilingues PE/FR } & \multicolumn{2}{|c|}{ Bilingues PB/FR } \\
\hline & & Pré-escolar & Escolar & Pré-escolar & Escolar & Pré-escolar & Escolar \\
\hline \multirow{3}{*}{ [-animado] } & clítico & $33,9 \%$ & $62,2 \%^{12}$ & $13,9 \%$ & $48,5 \%$ & - & $35,3 \%$ \\
\hline & omissão & $66,1 \%$ & $37,1 \%$ & $86,1 \%$ & $51,5 \%$ & $100 \%$ & $58,8 \%$ \\
\hline & pronome forte & - & $0,8 \%$ & - & - & - & $5,9 \%$ \\
\hline \multirow{3}{*}{ [+animado] } & clítico & $64,9 \%$ & $81,6 \% 13$ & $23,7 \%$ & $63 \%$ & - & $32,1 \%$ \\
\hline & omissão & $35,1 \%$ & $16,6 \%$ & $76,3 \%$ & $37 \%$ & $55 \%$ & $28,6 \%$ \\
\hline & pronome forte & - & $1,8 \%$ & - & - & $45 \%$ & $39,3 \%$ \\
\hline
\end{tabular}

Tabela 10 Resultados da variável animacidade obtidos para o contexto acusativo em ilha.

Analisando os resultados presentes nas tabelas 9 e 10, podemos concluir que a taxa de produção de clíticos/pronomes fortes é sempre mais elevada quando o antecedente é [+animado] e que a taxa de omissão é mais elevada quando o antecedente é [-animado]. No grupo PB/FR, o tipo de pronome produzido (forte ou clítico) é condicionado pela variável animacidade: os pronomes fortes surgem quase exclusivamente nos contextos [+ animado]. Neste grupo, os clíticos acusativos não reflexos quase não são produzidos em idade pré-escolar, ao passo que no grupo PE/FR há uma taxa mais alta de produção de clíticos, ainda que em taxas não muito elevadas, desde o pré-escolar.

Um teste de Wilcoxon permitiu-nos verificar que na condição de clítico acusativo em frase simples, considerando as taxas de produção de clíticos, a diferença entre [+animado] e [-animado] só revelou ser significativa para o grupo PE/FR. Os resultados obtidos para o grupo PB/FR encontram-se próximos do limiar da significância. Relativamente às taxas de omissão, a diferença entre [+animado] e [-animado] só é significativa para os grupos monolingues PE e PE/FR. Para a condição de clítico acusativo em ilhas, considerando as taxas de produção de clíticos, a diferença entre [+animado] e [-animado] revelou ser significativa para os três grupos.

\footnotetext{
${ }^{10} 1,2 \%$ correspondem à produção de clítico dativo.

${ }^{11} 6,4 \%$ correspondem à produção de clítico dativo.

${ }^{12} 8,5 \%$ correspondem à produção de clítico dativo.

${ }^{13} 17,7 \%$ correspondem à produção de clítico dativo.
} 
Relativamente às taxas de omissão, a diferença entre [+animado] e [-animado] revelou ser significativa para o grupo de monolingues PE e PB/FR, encontrando-se os resultados obtidos para o grupo PE/FR próximos do limiar da significância. Os valores de $p$ podem ser consultados na tabela 11:

\begin{tabular}{|c|c|c|c|c|c|c|}
\cline { 2 - 7 } \multicolumn{1}{c|}{} & \multicolumn{2}{c|}{ Monolingues PE } & \multicolumn{2}{c|}{ PE/FR } & \multicolumn{2}{c|}{ PB/FR } \\
\cline { 2 - 7 } \multicolumn{1}{c|}{} & clítico & omissão & clítico & omissão & clítico/p.forte & omissão \\
\hline Acus. f simples & 0.3065 & $<\mathbf{0 . 0 0 1}$ & $\mathbf{0 . 0 2 0 3 7}$ & $\mathbf{0 . 0 4 6 8 4}$ & $\underline{0.05334}$ & 0.1241 \\
\hline Acus. ilha & $<\mathbf{0 . 0 0 1}$ & $<\mathbf{0 . 0 0 1}$ & $\mathbf{0 . 0 1 7 9 1}$ & $\underline{0.0711}$ & $\mathbf{0 . 0 0 8 3 1 6}$ & $\mathbf{0 . 0 3 1 4 8}$ \\
\hline
\end{tabular}

Tabela 11 Valores de $p$ para a variável animacidade.

Em conclusão, podemos verificar que:

- há sensibilidade ao tipo de clítico em todos os grupos: os grupos bilingues e o grupo monolingue têm taxas de produção de clíticos/pronomes mais elevadas em contexto reflexo do que em contextos acusativos e há taxas de omissão superiores em contextos acusativos do que em contexto reflexo para bilingues e monolingues;

- há, em geral, sensibilidade ao contexto sintático: para a maioria dos grupos, a produção de pronomes é mais elevada em contexto de ilha;

- $\quad$ há sensibilidade a animacidade: em todos os grupos, a taxa de omissão é sempre mais elevada com antecedentes [-animados], ainda que as diferenças nem sempre sejam estatisticamente significativas ${ }^{14}$;

- há influência do fator idade: a taxa de produção de clíticos aumenta com consequente diminuição da taxa de omissão. No entanto, este efeito parece ter mais peso para o grupo de bilingues PE/FR e na condição de clítico acusativo em contexto de ilhas.

Verifica-se, assim, que o padrão de produção de clíticos/pronomes nos bilingues é globalmente similar ao padrão dos monolingues, mas que a taxa de omissão é mais elevada no grupo de bilingues.

O grupo PB/FR distingue-se do grupo PE/FR por apenas começar a produzir clíticos acusativos não reflexos em idade escolar e por ter também uma taxa de produção inferior de clíticos reflexos.

\section{Teste de colocação de clíticos}

\subsection{Metodologia}

\subsubsection{Participantes}

Participaram neste teste um total de $102 \operatorname{crianças~}^{15}$, com as seguintes características:

\begin{tabular}{|c|c|c|c|c|c|c|c|c|c|}
\cline { 2 - 9 } \multicolumn{1}{c|}{} & \multicolumn{3}{c|}{ Monolingues PE } & \multicolumn{3}{c|}{ Bilingues PE/FR } & \multicolumn{3}{c|}{ Bilingues PB/FR } \\
\cline { 2 - 9 } \multicolumn{1}{c|}{} & $\mathbf{N}^{\mathbf{0}}$ & $\begin{array}{c}\text { Intervalo } \\
\text { Idades }\end{array}$ & $\begin{array}{c}\text { Média } \\
\text { Idades }\end{array}$ & $\mathbf{N}^{\mathbf{0}}$ & $\begin{array}{c}\text { Intervalo } \\
\text { Idades }\end{array}$ & $\begin{array}{c}\text { Média } \\
\text { idades }\end{array}$ & $\mathbf{N}^{\mathbf{o}}$ & $\begin{array}{c}\text { Intervalo } \\
\text { idades }\end{array}$ & $\begin{array}{c}\text { Média } \\
\text { idades }\end{array}$ \\
\hline Pré-escolar & 11 & $3-6$ anos & $\begin{array}{c}4,7 \\
(\mathrm{DP}=0,9)\end{array}$ & 5 & $4-5$ anos & $\begin{array}{c}4,5 \\
(\mathrm{DP}=0,6)\end{array}$ & 5 & 5 anos & - \\
\hline Escolar & 50 & $6-10$ anos & $\begin{array}{c}7,4 \\
(\mathrm{DP}=1,1)\end{array}$ & 17 & $6-11$ anos & $\begin{array}{c}8,6 \\
(\mathrm{DP}=1,5)\end{array}$ & 14 & $6-11$ anos & $\begin{array}{c}8,6 \\
(\mathrm{DP}=1,5)\end{array}$ \\
\hline
\end{tabular}

Tabela 8 Participantes do teste de colocação de clíticos ${ }^{16}$.

\footnotetext{
${ }^{14}$ As diferenças não são significativas para o grupo PB/FR no contexto acusativo em frases simples e para o grupo PE/FR no contexto acusativo em ilhas os resultados estão próximos do limiar da significância.

15 Os participantes do grupo de monolingues são os mesmos que realizaram o teste de produção de clíticos, exceto um. 18 dos participantes do grupo de bilingues realizaram apenas este teste de colocação. Os restantes realizaram ambas as tarefas.
} 
Todas as crianças bilingues são falantes de herança de português, de segunda geração, residentes em França. Estas crianças frequentam o ensino regular francês no Lyceé International Saint-Germain-en-Laye e na École Maternelle et Primaire Normandie-Niémen - Le Pecq. Duas vezes por semana, num total de 6 horas, frequentam aulas de português. A variedade falada pela professora nas aulas é o PE. Todas as crianças estão expostas ao português (variedade europeia ou brasileira) e ao francês em casa.

As crianças monolingues residem na área metropolitana de Lisboa e frequentam a Escola Básica do Bairro da Covina (Santa Iria de Azoia, Loures).

\subsubsection{Procedimento}

Para testar a aquisição da colocação de clíticos em PE por crianças bilingues, adaptámos a tarefa do estudo de Costa, Fiéis e Lobo (2015), retirando o contexto de coordenação (ênclise) e acrescentando um novo contexto de subordinação (próclise) - o de orações subordinadas completivas com indicativo.

O teste continha 40 itens ( 4 de treino e 36 de teste) que induziam a produção de um clítico em diferentes contextos de próclise e em contextos de ênclise distribuídos pelas seguintes condições:
a) Frases simples sem proclisador (ênclise) - 8 itens;
b) Frases simples com negação (próclise) - 4 itens;
c) Frases simples com sujeitos negativos 'ninguém' (próclise) - 4 itens;
d) Frases simples com sujeitos DP quantificados 'todos' (próclise) - 4 itens;
e) Frases simples com advérbio 'já' (próclise) - 4 itens;
f) Orações completivas modo indicativo (próclise) - 4 itens;
g) Orações completivas modo conjuntivo (próclise) - 4 itens;
h) Orações subordinadas adverbiais com 'porque’ (próclise) - 4 itens.

Sabe-se, de estudos anteriores, que o clítico se é o que deixa de ser omitido mais cedo e o que apresenta menores taxas de omissão (Silva, 2008). Isto mesmo foi verificado em Nardelli \& Lobo (2018), para bilingues português-espanhol, e no nosso primeiro estudo com bilingues português-francês (ver secção 3.). Por este mesmo motivo, neste teste, só foi utilizado o clítico se.

Todos os participantes foram testados individualmente, as respostas foram anotadas numa folha de registo, gravadas em formato de áudio e posteriormente transcritas e codificadas num ficheiro Excel. Após a apresentação de uma imagem em computador, pedia-se ao participante que respondesse a uma questão ou que completasse uma frase.

Apresentamos, de seguida, duas imagens representativas das condições desta tarefa.

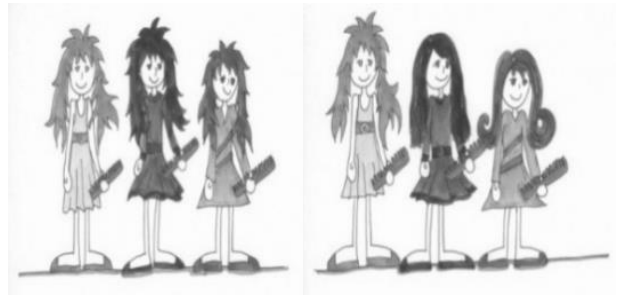

Figura 6 Exemplo da condição frase simples com negação (próclise).

${ }_{16}$ Investigador: [imagem da direita] Estas duas meninas usaram o pente e estão agora penteadas. Mas esta menina continua despenteada. O que é que ela não fez? Resposta esperada: PE/PB Não se penteou.
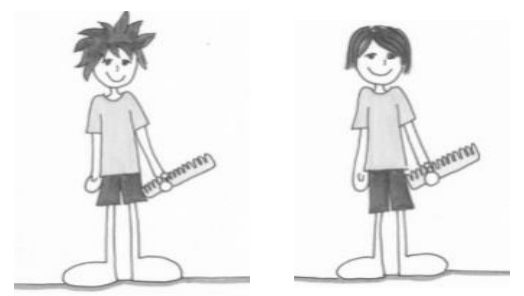

Figura 7 Exemplo da condição frase simples sem proclisador (ênclise).

Investigador: [imagem da esquerda] Este menino está tododespenteado. [imagem da direita] Mas tem um pente na mão. O que é que o menino fez?

Resposta esperada: PE Penteou-se. | PB Se penteou. 


\subsubsection{Análise estatística}

Para verificar se as diferenças encontradas são estatisticamente significativas recorremos ao teste nãoparamétrico de Wilcoxon no programa $R$. Para variáveis intrassujeitos usamos o paired samples Wilcoxon test e para as variáveis intersujeitos usámos o unpaired two-samples Wilcoxon test.

\subsection{Resultados}

Nas tabelas 13 e 14 podemos observar os dados relativos aos resultados globais obtidos para os contextos de ênclise e de próclise.

\begin{tabular}{|c|c|c|c|c|c|c|}
\cline { 2 - 7 } \multicolumn{1}{c|}{} & \multicolumn{2}{c|}{ Monolingues PE } & \multicolumn{2}{c|}{ PE/FR } & \multicolumn{2}{c|}{ PB/FR } \\
\cline { 2 - 7 } \multicolumn{1}{c|}{} & Pré-escolar & Escolar & Pré-escolar & Escolar & Pré-escolar & Escolar \\
\hline ênclise & $81,8 \%$ & $84,8 \%$ & $27,5 \%$ & $72,1 \%$ & $20 \%$ & $21,4 \%$ \\
\hline omissão & $4,5 \%$ & $2,7 \%$ & $22,5 \%$ & $2,9 \%$ & $27,5 \%$ & $12,5 \%$ \\
\hline outra & $13,6 \%$ & $8,3 \%$ & $32,5 \%$ & $9,6 \%$ & $17,5 \%$ & $13,4 \%$ \\
\hline próclise & - & $4,2 \%$ & $17,5 \%$ & $15,4 \%$ & $35 \%$ & $52,7 \%$ \\
\hline
\end{tabular}

Tabela 13 Resultados globais obtidos para os contextos de ênclise.

\begin{tabular}{|c|c|c|c|c|c|c|}
\cline { 2 - 7 } \multicolumn{1}{c|}{} & \multicolumn{2}{c|}{ Monolingues PE } & \multicolumn{2}{c|}{ PE/FR } & \multicolumn{2}{c|}{ PB/FR } \\
\cline { 2 - 7 } \multicolumn{1}{c|}{} & $\begin{array}{c}\text { Pré- } \\
\text { escolar }\end{array}$ & Escolar & $\begin{array}{c}\text { Pré- } \\
\text { escolar }\end{array}$ & Escolar & $\begin{array}{c}\text { Pré- } \\
\text { escolar }\end{array}$ & Escolar \\
\hline ênclise & $54,9 \%$ & $42,9 \%$ & $11,4 \%$ & $45,2 \%$ & $10 \%$ & $18,6 \%$ \\
\hline omissão & $11,4 \%$ & $2,5 \%$ & $14,3 \%$ & $3,6 \%$ & $20 \%$ & $10,5 \%$ \\
\hline outra & $13,6 \%$ & $6,3 \%$ & $35 \%$ & $6,1 \%$ & $17,1 \%$ & $9,4 \%$ \\
\hline próclise & $20,1 \%$ & $47,7 \%$ & $39,3 \%$ & $42,6 \%$ & $50 \%$ & $60,7 \%$ \\
\hline redobro & - & $0,6 \%$ & - & $2,5 \%$ & $1,4 \%$ & $0,8 \%$ \\
\hline $\begin{array}{c}\text { pronome } \\
\text { forte }\end{array}$ & - & - & - & - & $1,4 \%$ & - \\
\hline
\end{tabular}

Tabela 14 Resultados globais obtidos para os contextos de próclise.

Considerando os resultados presentes nas tabelas 13 e 14, podemos concluir que:

- Há registo de taxas de próclise em contexto de ênclise, com maior predomínio nos grupos bilingues;

- Há registo de taxas de ênclise em contextos de próclise, em todos os grupos;

- Os casos de redobro e de pronome forte são residuais.

Se considerarmos apenas as respostas com clíticos, obtemos os resultados presentes na tabela 15 : 


\begin{tabular}{|c|c|c|c|c|c|c|c|}
\cline { 3 - 8 } \multicolumn{2}{c|}{} & \multicolumn{2}{c|}{ Monolingues PE } & \multicolumn{2}{c|}{ PE/FR } & \multicolumn{2}{c|}{ PB/FR } \\
\cline { 2 - 8 } \multicolumn{2}{c|}{} & Pré-escolar & Escolar & Pré-escolar & Escolar & Pré-escolar & Escolar \\
\hline \multirow{3}{*}{ Contextos de ênclise } & ênclise & $100 \%$ & $95,3 \%$ & $61,1 \%$ & $82,4 \%$ & $36,4 \%$ & $28,9 \%$ \\
\cline { 2 - 8 } & próclise & - & $4,7 \%$ & $38,9 \%$ & $17,6 \%$ & $63,6 \%$ & $71,1 \%$ \\
\hline \multirow{3}{*}{ Contextos de próclise } & ênclise & $73,2 \%$ & $47,1 \%$ & $22,5 \%$ & $50 \%$ & $16,3 \%$ & $23,2 \%$ \\
\cline { 2 - 8 } & próclise & $26,8 \%$ & $52,3 \%$ & $77,5 \%$ & $47,2 \%$ & $81,4 \%$ & $75,8 \%$ \\
\cline { 2 - 8 } & redobro & - & $0,6 \%$ & - & $2,8 \%$ & $2,3 \%$ & $1 \%$ \\
\hline
\end{tabular}

Tabela 15 Resultados obtidos para os contextos de próclise e ênclise considerando apenas as respostas com clíticos.

Observando os resultados presentes na Tabela 15, podemos verificar que, nos contextos de ênclise, no grupo de monolingues e no grupo de bilingues PE/FR, existe preferência pela ênclise (monolingues PE: $p<$ 0.001: PE/FR: $p<0.001$ ), embora com registo de ocorrência de próclise com maior predominância no grupo de bilingues PE/FR. Contrariamente ao que ocorre no grupo de monolingues e de bilingues PE/FR, o grupo de bilingues PB/FR apresenta preferência pela próclise neste contexto $(p<0.001)$, ainda que também haja registo de ênclise. ${ }^{17}$

Considerando os resultados obtidos nos contextos de próclise, o grupo de monolingues revela dois comportamentos distintos: o grupo de crianças do nível pré-escolar apresenta preferência pela ênclise ( $p<$ 0.001); o grupo de crianças do nível escolar apresenta um padrão de comportamento que oscila ente a próclise $(52,3 \%)$ e a ênclise $(47,1 \%)^{18}$. No grupo de bilingues PE/FR podemos verificar que do grupo pré-escolar para o grupo escolar a taxa de ênclise aumenta $(p=0.002454)$ e a taxa de próclise diminui, embora sem diferença significativa $(p=0.599)$. Podemos verificar que a generalização da ênclise ocorre mais tarde do que no grupo de monolingues, uma vez que no grupo de monolingues a taxa de ênclise diminui do grupo pré-escolar para o grupo escolar e no grupo PE/FR ocorre o oposto. O grupo de bilingues PB/FR revela preferência pela próclise $(p<0.001)$. Verificamos que existe ocorrência de ênclise, no entanto esta ocorre em menor taxa do que no grupo de monolingues e no grupo de bilingues PE/FR.

Outro dado relevante é o facto de globalmente os bilingues PE/FR apresentarem taxas de próclise superiores às registadas para o grupo de monolingues, quer em contexto de ênclise quer em contextos de próclise. No entanto, a diferença só revela ser significativa no contexto de ênclise (contexto de ênclise: $p=$ 0.001924; contexto de próclise: $p=0.176$ ).

Uma análise dos resultados individuais mostra que nas crianças bilingues PE/FR apenas duas crianças do grupo pré-escolar e três do escolar produziram próclise em contexto de ênclise, havendo também variação individual nos contextos de próclise (Gráficos 1 e 2).

\footnotetext{
${ }^{17}$ Relembramos que a variante falada pela professora nas aulas é o PE.

${ }^{18}$ Sabemos de estudos anteriores, como os de Duarte, Matos \& Faria (1995), Duarte \& Matos (2000) e Costa, Fiéis \& Lobo (2015), que na aquisição do PE há tendência para generalização da ênclise em contextos de próclise.
} 


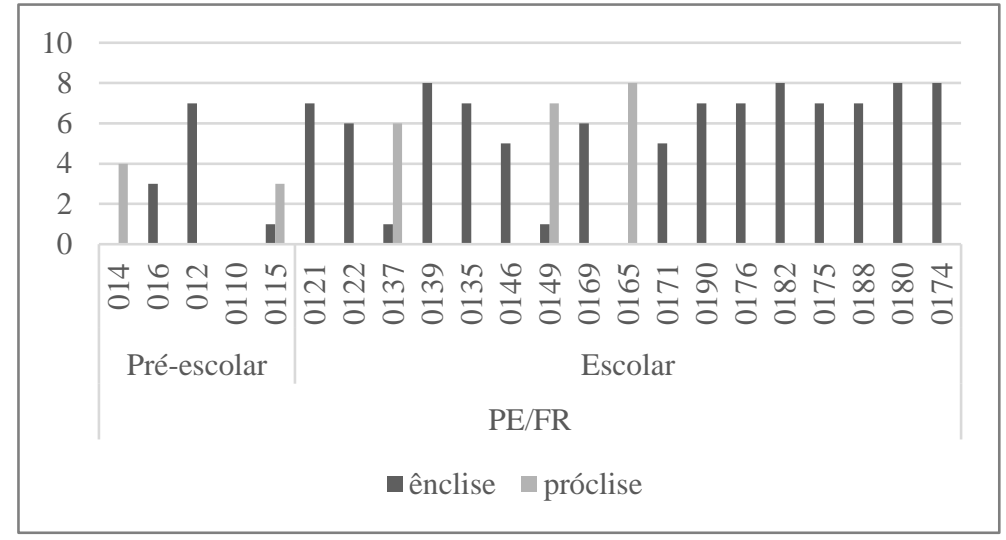

Gráfico 1 Resultados individuais: ocorrências de ênclise e próclise em contexto de ênclise no grupo PE/FR.

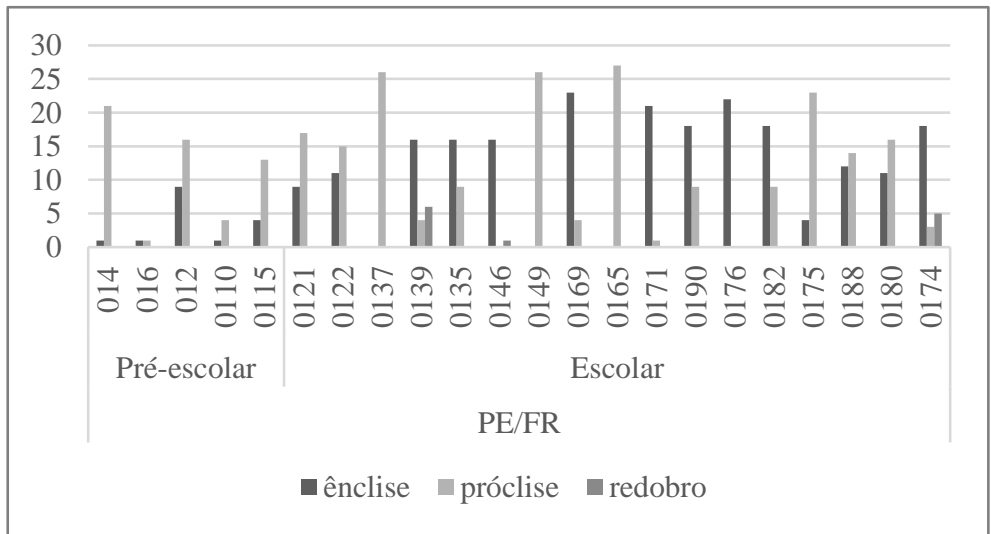

Gráfico 2 Resultados individuais: ocorrências de ênclise e próclise em contexto de próclise no grupo PE/FR.

No grupo PB/FR, em contexto de ênclise, apenas uma criança do grupo pré-escolar e 6 crianças do grupo escolar produzem alguma taxa de ênclise, sendo a ênclise categórica na criança do pré-escolar e em 3 crianças do grupo escolar; para a maioria das crianças, a próclise é categórica (Gráfico 3). Em contexto de próclise, há apenas 3 crianças em que a ênclise é maioritária, havendo 10 crianças com próclise categórica (Gráfico 4). 


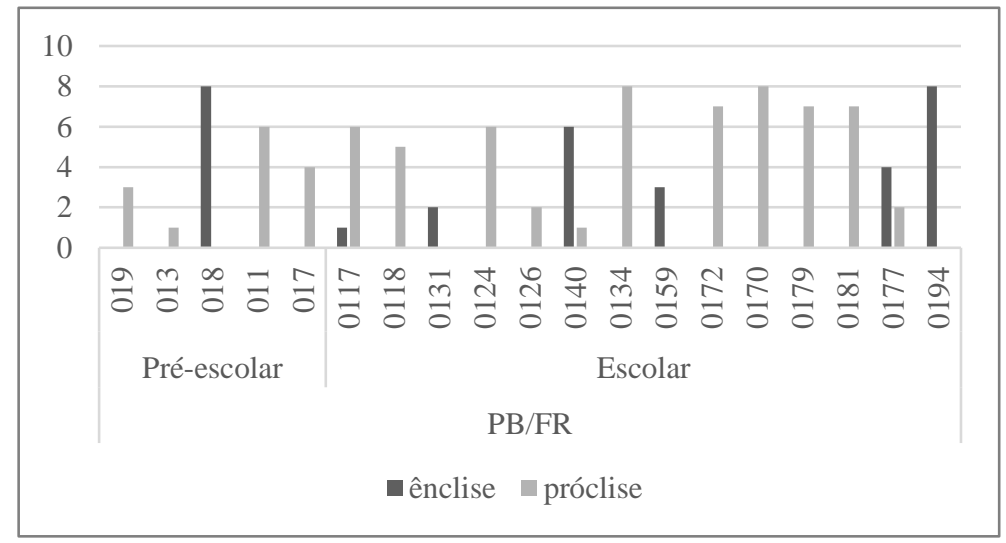

Gráfico 3 Resultados individuais: ocorrências de ênclise e próclise em contexto de ênclise no grupo PB/FR.

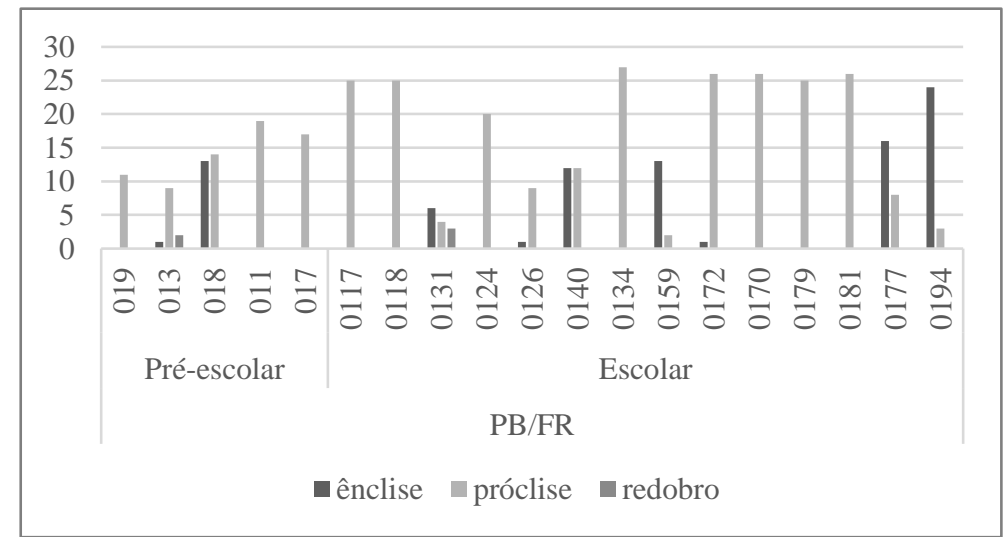

Gráfico 4 Resultados individuais: ocorrências de ênclise e próclise em contexto de próclise no grupo PB/FR.

Considerando agora os diferentes contextos de próclise, obtemos os seguintes resultados. Na tabela 12, podemos ver as taxas de próclise obtidas para cada uma das condições de próclise:

\begin{tabular}{|c|c|c|c|c|c|c|}
\cline { 2 - 7 } \multicolumn{1}{c|}{} & \multicolumn{2}{c|}{ Monolingues PE } & \multicolumn{2}{c|}{ PE/FR } & \multicolumn{2}{c|}{ PB/FR } \\
\cline { 2 - 7 } & $\begin{array}{c}\text { Pré- } \\
\text { escolar }\end{array}$ & Escolar & $\begin{array}{c}\text { Pré- } \\
\text { escolar }\end{array}$ & Escolar & $\begin{array}{c}\text { Pré- } \\
\text { escolar }\end{array}$ & Escolar \\
\hline Advérbio já & $30,6 \%$ & $56,6 \%$ & $38,9 \%$ & $17,6 \%$ & $63,6 \%$ & $71,1 \%$ \\
\hline Negação & $57,6 \%$ & $84,5 \%$ & $90,9 \%$ & $67,2 \%$ & $100 \%$ & $82,9 \%$ \\
\hline Subordinada Adverbial & $5,4 \%$ & $38,7 \%$ & $55,6 \%$ & $31 \%$ & $60 \%$ & $74,4 \%$ \\
\hline $\begin{array}{c}\text { Subordinada Completiva } \\
\text { (Conjuntivo) }\end{array}$ & $46,7 \%$ & $68,2 \%$ & $90,9 \%$ & $76,7 \%$ & $83,3 \%$ & $93,3 \%$ \\
\hline
\end{tabular}




\begin{tabular}{|c|c|c|c|c|c|c|}
\cline { 2 - 7 } Subordinada Completiva (Indicativo) & $7,7 \%$ & $35 \%$ & $66,7 \%$ & $26,8 \%$ & $75 \%$ & $65,9 \%$ \\
\hline Sujeito DP quantificado & $8,6 \%$ & $21,9 \%$ & $41,7 \%$ & $24,6 \%$ & $50 \%$ & $74,5 \%$ \\
\hline Sujeito Pronome Negativo & $32,4 \%$ & $59,8 \%$ & $100 \%$ & $53 \%$ & $90,9 \%$ & $73,9 \%$ \\
\hline
\end{tabular}

Tabela 16 Taxas de próclise por condição.

Como podemos ver na tabela 16 , as taxas de próclise não são iguais em todos os contextos. De forma geral, podemos concluir que, para todos os grupos, os primeiros contextos a serem adquiridos são os contextos com negação, de subordinada completiva com conjuntivo e de sujeito pronome negativo. No PB, há uma diferença mais marcada entre contextos no grupo pré-escolar do que no grupo escolar: as taxas de próclise baixam com negação, sujeito negativo e completiva com indicativo, mas aumentam nos restantes contextos. Já no grupo PE/FR as taxas de próclise baixam do grupo pré-escolar para o escolar em todos os contextos. Comparando os grupos bilingues entre si, podemos ver que as taxas de próclise são sempre superiores para o grupo PB/FR, com exceção do grupo pré-escolar nas condições subordinada completiva com conjuntivo e sujeito pronome negativo.

Neste teste introduzimos uma condição que não tinha sido testada no estudo de Costa, Fiéis \& Lobo (2015) - a condição de subordinada completiva com o modo indicativo. Neste tipo de condição, segundo a gramática adulta do PE, espera-se encontrar próclise. No entanto, e segundo Martins (2013), é um contexto em que se encontra maior variação nas produções adultas e em que se sabe que existe mais ênclise do que em outros contextos de subordinação.

Os resultados obtidos para esta condição estão presentes na tabela 17:

\begin{tabular}{|c|c|c|c|c|c|c|c|}
\cline { 3 - 8 } \multicolumn{2}{c|}{} & \multicolumn{2}{c|}{ Monolingues PE } & \multicolumn{2}{c|}{ PE/FR } & \multicolumn{2}{c|}{ PB/FR } \\
\cline { 3 - 8 } \multicolumn{2}{c|}{} & Pré-escolar & Escolar & Pré-escolar & Escolar & Pré-escolar & Escolar \\
\hline $\begin{array}{c}\text { Subordinada } \\
\text { Completiva (Conjuntivo) }\end{array}$ & ênclise & $53,3 \%$ & $31,3 \%$ & $9,1 \%$ & $21,7 \%$ & $16,7 \%$ & $6,7 \%$ \\
\cline { 2 - 8 } & próclise & $46,7 \%$ & $68,2 \%$ & $90,9 \%$ & $76,7 \%$ & $83,3 \%$ & $93,3 \%$ \\
\hline $\begin{array}{c}\text { Subordinada } \\
\text { Completiva (Indicativo) }\end{array}$ & ênclise & $92,3 \%$ & $64,4 \%$ & $33,3 \%$ & $72,3 \%$ & $25 \%$ & $31,7 \%$ \\
\cline { 2 - 8 } & próclise & $7,7 \%$ & $35 \%$ & $66,7 \%$ & $26,8 \%$ & $75 \%$ & $65,9 \%$ \\
\hline
\end{tabular}

Tabela 17 Taxas de ênclise e de próclise para as condições subordinada completiva conjuntivo e indicativo.

Como podemos ver, as taxas de ênclise são mais elevadas na condição de subordinada completiva no modo indicativo do que no modo conjuntivo, com diferença significativa para os grupos de monolingues PE e bilingues PE/FR (Monolingues PE: $\mathrm{p}<0.001$; PE/FR: $\mathrm{p}=0.003434$ ) e com uma diferença próxima do limiar da significância para o grupo de bilingues PB/FR ( $p=0.0734)$, o que está de acordo com a descrição feita por Martins (2013).

\section{Discussão e conclusões}

Retomando as questões de investigação enunciadas na secção 2.6., vejamos quais as conclusões a que os dados do nosso estudo nos permitem chegar.

Será que o desenvolvimento do português das crianças bilingues português-francês é semelhante ao dos monolingues? Verificámos que sim. No entanto, o desenvolvimento do grupo de bilingues dá-se de forma mais lenta do que o do grupo de monolingues. Este desenvolvimento mais lento pode, tal como referido em 
Pirvulescu et al. (2014), ser atribuído a um "efeito bilingue". Nos falantes bilingues certas propriedades gramaticais desenvolvem-se mais lentamente devido ao facto de estes estarem sujeitos não só a uma maior ambiguidade presente no input que recebem das duas línguas, bem como a um input mais reduzido em cada uma das línguas. Tal como em estudos anteriores, que abordaram a problemática da omissão de objeto com crianças bilingues (Paradis et al., 2003; Pirvulescu et al., 2014; Nardelli \& Lobo, 2018), também os bilingues aqui em estudo têm taxas de omissão mais elevadas do que os monolingues e mostram que a generalização da ênclise, comportamento típico do desenvolvimento monolingue, ocorre mais tardiamente. Tal como acontece no desenvolvimento monolingue (Duarte, Matos \& Faria, 1995; Duarte \& Matos, 2000 e Costa, Fiéis \& Lobo, 2015), também os bilingues fazem uso da ênclise em contextos de próclise, embora com uma ocorrência mais baixa do que no contexto de ênclise. Os falantes bilingues adquirem os contextos de próclise de forma gradual, tal como os monolingues (Costa, Fiéis \& Lobo, 2015).

A animacidade, o tipo de clítico (reflexo vs. não-reflexo) e o contexto sintático (frase simples vs. ilha) exercem influência na omissão de clíticos? Os falantes bilingues mostram ser sensíveis a estas variáveis, tal como os monolingues. Foram registadas taxas de produção de clítico mais elevadas em contexto reflexo do que em contextos não-reflexos, tal como no estudo com monolingues PE de Costa \& Lobo (2007), e paralelamente a isto, taxas de omissão mais elevadas em contextos acusativos do que em contextos reflexos. Relativamente ao contexto sintático, verificámos que existe mais produção de clíticos em ilhas do que em frases simples. Podemos, assim, concluir que o desenvolvimento bilingue segue, na generalidade, um padrão semelhante ao do monolingue.

No que diz respeito à variável animacidade, ainda que as diferenças não sejam estatisticamente significativas para todos os grupos ${ }^{19}$, podemos verificar que a taxa de omissão é mais elevada quando o antecedente é [-animado] e a taxa de produção de clíticos/pronome forte é mais elevada quando o antecedente é [+animado], confirmando estudos anteriores de Lopes \& Cyrino (2005), para o PB, e Duarte \& Costa (2013), para o PE e Rinke, Flores \& Sopata (2019), para os bilingues português/alemão.

Existe influência do francês no português na colocação de clíticos? Sim, para algumas crianças, mas não para todas. Se olharmos para os resultados de grupo, verificamos que o grupo PE/FR tem taxas de próclise superiores às registadas para os monolingues, quer em contextos de ênclise quer em contextos de próclise. No entanto, só em contextos de ênclise é que esta diferença é estatisticamente significativa. Também Flores, Barbosa \& Casa Nova (2016) encontraram resultados idênticos com falantes bilingues PE/francês - taxas elevadas de próclise em contextos de próclise; produção de próclise em contextos de ênclise. No grupo préescolar PE/FR, a extensão da próclise é mais notória. Poderíamos assim concluir que uma criança que recebe input de francês, que é como se sabe uma língua de próclise dominante, e de português, que tem alguma próclise, irá demorar mais tempo a determinar os contextos em que deve fazer uso da próclise ou da ênclise. O facto de o francês ser uma língua de próclise dominante pode facilitar a estabilização mais precoce da próclise e dificultar o uso devido da ênclise. Contudo, a análise individual dos resultados, que não pudemos aqui desenvolver, mostra que há padrões distintos e que será necessário apurar que outras variáveis estão a determinar o comportamento dos bilingues.

Tal como em trabalhos anteriores (Costa, Fiéis \& Lobo, 2015, para os monolingues, e Flores, Barbosa \& Casa Nova, 2016, para os bilingues), verificámos que há desenvolvimento progressivo dos contextos de próclise. Não há absoluta coincidência entre contextos mais precoces e mais tardios nos grupos monolingue e bilingue, mas, em geral, os contextos negativos (negação e sujeito negativo) e o de subordinada completiva com conjuntivo são contextos em que as taxas de próclise são mais elevadas. Na condição que não tinha sido

\footnotetext{
${ }^{19}$ No grupo de monolingues PE para a taxa de produção de clíticos em contexto acusativo com frases simples e no grupo PB/FR para a taxa de omissão em contexto acusativo com frases simples não existe diferença significativa entre [+animado] e [-animado]. No grupo de bilingues PB/FR para a taxa de produção de clíticos em contexto acusativo com frases simples e no grupo de bilingues PE/FR para a taxa de omissão em contexto de clítico acusativo com ilhas a diferença entre [+animado] e [-animado] está próxima do limiar da significância.
} 
testada no estudo de Costa, Fiéis \& Lobo (2015) - a condição de subordinada completiva com o modo indicativo - confirmámos que as taxas de ênclise são superiores nos grupos de monolingues e no grupo PE/FR, tal como esperado tendo em conta Martins (2013).

Há diferenças entre crianças falantes de diferentes variedades do português (PE vs. PB)? Os resultados obtidos apontam para uma resposta afirmativa a esta pergunta. Olhando para os resultados, podemos concluir que: os falantes de PB/FR fazem mais uso da próclise do que os falantes PE/FR; a estratégia de substituição da produção de clíticos por pronome forte só ocorre no grupo PB/FR; a taxa de produção de clíticos nos falantes PE/FR é superior à dos falantes PB/FR. No entanto, também no grupo PB/FR a análise individual dos resultados mostra que há padrões distintos: alguns dos bilingues PB/FR têm taxas elevadas de produção de ênclise, o que poderá resultar da exposição formal ao PE. Em trabalho futuro contamos explorar as variáveis que podem estar a condicionar as diferenças individuais encontradas.

Retomando a proposta de Müller \& Hulk (2001), que propõem que as áreas que envolvem a interface sintaxe-discurso/pragmática e em que há ambiguidade ou sobreposição estrutural dos dois sistemas são áreas vulneráveis no desenvolvimento bilingue com possível ocorrência de transferência entre línguas, verificámos, através dos nossos dados, que esta hipótese é demasiado forte. Na verdade, verificámos que existe mais omissão no grupo dos bilingues do que no dos monolingues, mesmo quando o francês não dispõe da construção de objeto nulo, tal como observado em estudos anteriores com bilingues (e.g. Pirvulescu et al., 2014; Nardelli \& Lobo, 2018), mas também que existe transferência no fenómeno de colocação de clíticos, contra aquilo que seria esperado pela hipótese de Müller \& Hulk (2001) - a colocação de clíticos em PE não é condicionada por fatores discursivos, ao contrário do fenómeno de omissão de clíticos. Podemos assim concluir que esta hipótese é demasiado restritiva. A colocação de clíticos, que não envolve a interface sintaxediscurso, mas possivelmente envolve desenvolvimento ao nível lexical, pela determinação dos itens lexicais e funcionais que determinam o uso da próclise, também pode ser vulnerável à interferência linguística. Na verdade, quer o fenómeno de produção/omissão de clíticos, quer o fenómeno de colocação de clíticos são áreas em que existe variação sincrónica e diacrónica no sistema do português. A colocação de clíticos é um fenómeno de desenvolvimento tardio também na aquisição monolingue do PE (Costa, Fiéis \& Lobo, 2015) e esta vulnerabilidade manifesta-se também no desenvolvimento bilingue.

Globalmente, o nosso estudo confirma os resultados de estudos anteriores e mostra que o desenvolvimento bilingue não difere substancialmente do desenvolvimento monolingue, havendo sensibilidade a tipo de clítico e contexto sintático. Pode, contudo, haver um desenvolvimento mais lento na produção de clíticos (taxas de omissão superiores nos grupos de bilingues relativamente aos monolingues) e alguma interferência, que se manifesta em taxas significativamente mais altas de produção de próclise em contextos de ênclise. Deverá, contudo, ser explorado o efeito de outras variáveis (e.g. dominância linguística) nestes resultados, uma vez que o grupo de bilingues apresenta resultados heterogéneos.

\section{Agradecimentos}

Agradecemos a todas as crianças que participaram no nosso estudo e aos encarregados de educação que autorizaram a sua participação. Agradecemos também à Coordenadora do Ensino de Português em França, Professora Adelaide Cristóvão, ao diretor da Secção Portuguesa do Lyceé International Saint-Germain-enLaye, Professor José Carlos Janela, ao Diretor do Agrupamento de Escolas de Santa Iria de Azóia, Professor António Marcelino, à Coordenadora da Escola Básica do Bairro da Covina, Professora Isabel Teixeira bem como a todos os Professores. Agradecemos à Joana Teixeira pela ajuda na estatística. 


\section{Referências}

Agathocleous, Marina, Alexandra Charalambous, Elena Papadopoulou \& Kleanthes K Grohmann (2014) The role of the social environment on linguistic development: a view from Cypriot Greek clitic placement. In Kleanthes K. Grohmann e Theoni Neokleous (orgs.) Developments in the Acquisition of Clitics. Newcastle: Cambridge Scholars Publishing, pp. 41-86

Almeida, Letícia \& Cristina Flores (2017) Bilinguismo. In Maria João Freitas e Ana Lúcia Santos (orgs.) Aquisição de Língua Materna e Não Materna. Questões Gerais e Dados do Português. Textbooks in Language Science. Berlin: Language Science Press, pp. 275-304.

Barbosa, Pilar \& Cristina Flores (2011) Clíticos no português de herança de emigrantes bilingues de segunda geração. Textos Seleccionados do XXVI Encontro Nacional da Associação Portuguesa de Linguística. Lisboa: APL, pp 81-98.

Bianchi, Valentina \& Maria Cristina Figueiredo Silva (1994) On some properties of agreement-object in Italian and Brazilian Portuguese. In Michael L. Mazzola (org.). Issues and Theory in Romance Linguistics. Selected papers from the Linguistic Symposium on Romance Languages XXIII. Washington, DC: Georgetown University Press, pp. 181-197.

Brito, Ana Maria, Inês Duarte \& Gabriela Matos (2003) Tipologia e distribuição das expressões nominais. In Maria Helena Mira Mateus, Ana Maria Brito, Inês Duarte Isabel Hub Faria, Sónia Frota, Gabriela Matos, Fátima Oliveira, Marina Vigário e Alina Villalva. Gramática da Língua Portuguesa. Lisboa: Caminho, pp. 796-867.

Carmona, Jaqueline, \& Carolina Silva (2007) A aquisição de clíticos dativos em PE: teste piloto. Textos seleccionados do XXII Encontro Nacional da Associação Portuguesa de Linguística. Lisboa: APL, pp. 199-210.

Casa Nova, Manuela (2015) Formas de realização do pronome clítico em português europeu por falantes de herança luso-franceses. Revista Diacrítica 29 (1), pp. 113-145.

Castro, Tammer, Jason Rothman \& Marit Westergaard (2017) On the directionality of cross-linguistic effects in bidialectal bilingualism. Frontiers in psychology 8:1382.

Chillier, Laurence, Marina Arabatzi, Lara Baranzini, Stéphany Cronel-Ohayon, Thierry Deonna, S. Dubé, Julie Franck, Ulrich Frauenfelder, Cornelia Hamann, Luigi Rizzi, Michal Starke \& Pascal Zesiger (2001) The acquisition of French pronouns in normal children and in childrenwith specific language impairment (SLI). In Proceedings of Early Lexicon Acquisition (ELA), CD-Rom. Lyon, 5-8 Dezembro.

Costa, João, Alexandra Fiéis \& Maria Lobo (2015) Input variability and late acquisition: clitic misplacement in European Portuguese. Lingua 161, pp.10-26.

Costa, João \& Maria Lobo (2006) A aquisição de clíticos em PE: omissão de clíticos ou objecto nulo. Textos Seleccionados do XXI Encontro Nacional da Associação Portuguesa de Linguística. Lisboa: APL, pp. 285-293.

Costa, João \& Maria Lobo (2007) Complexidade e omissão de clíticos: o caso dos reflexos. Textos Seleccionados do XXII Encontro Nacional da Associação Portuguesa de Linguística. Lisboa: APL, pp. 303-313.

Costa, João \& Maria Lobo (2010) Compreensão de objecto nulo em contextos transitivos e reflexos na aquisição do português europeu. Textos Seleccionados do XXV Encontro Nacional da Associação Portuguesa de Linguística. Lisboa: APL, pp. 339-350.

Costa, João, Maria Lobo \& Carolina Silva (2009) Null objects and early pragmatics in the acquisition of European Portuguese. Probus 21 (2), pp. 143-162.

Costa, João, Maria Lobo \& Fernanda Pratas (2013) Produção de clíticos por crianças bilingues e monolingues. Textos Selecionados do XXVIII Encontro Nacional da Associação Portuguesa de Linguística. Lisboa: APL, 289-306. 
Cummins, Sarah, \& Yves Roberge (2004) Null objects in French and English. In Julie Auger, J. Clancy Clements \& Barbara Vence (orgs.) Contemporary approaches to Romance linguistics. Amsterdam: John Benjamins, pp. 121-138.

Cummins, Sarah, \& Yves Roberge (2005) A Modular account of null objects in French. Syntax 8 (1), pp. 4464.

Cyrino, Sónia (2001) O objeto nulo no português do Brasil e no português de Portugal. Boletim da ABRALIN 25, pp. 173-181.

Cyrino, Sonia \& Ruth Lopes (2012) Null objects as ellipsis. Going Romance 2012. Leuven, Belgium.

Duarte, Inês \& Gabriela Matos (2000) Romance clitics and the minimalist program. In João Costa (org.) Portuguese syntax: New comparative studies. Oxford/New York: Oxford University Press, pp. 116-142.

Duarte, Inês \& João Costa (2013) Objeto Nulo. In Eduardo Paiva Raposo, Maria Fernanda Bacelar do Nascimento, Maria Antónia Mota, Luísa Segura e Amália Mendes (orgs.) Gramática do Português. Lisboa: Fundação Calouste Gulbenkian, pp. 2339-2348.

Duarte, Inês, Gabriela Matos \& Isabel Hub Faria (1995) Specificity of European Portuguese Clitics in Romance. In Isabel Hub Faria e Maria João Freitas (orgs.) Studies in the Acquisition of Portuguese. Lisboa: APL/Colibri, pp. 129-154.

Flores, Cristina (2017) Bilinguismo infantil. Um legado valioso do fenómeno migratório luso-alemão. Diacrítica, 31(3), pp. 237-250.

Flores, Cristina, Ana Lúcia Santos, Alice Jesus \& Rui Marques (2017) Age and input effects in the acquisition of mood in Heritage Portuguese. Journal of child language, 44(4), pp. 795-828.

Flores, Cristina \& Pilar Barbosa (2014) When reduced input leads to delayed acquisition: a study on the acquisition of clitic placement by Portuguese heritage speakers. International Journal of Bilingualism 18 (3), pp. 304-325.

Flores, Cristina, Pilar Barbosa \& Manuela Casa Nova (2016) A Closer Look at Cross-Linguistic Influence in the Acquisition of Portuguese as a Heritage Language. In Sambor Grucza, Magdalena Olpinska-Szkieko e Pitor Romanowski (orgs.) Bilingual Landscape of the Contemporary World. Frankfurt/Main, London, New York: Peter Lang Verlag, pp. 75-94.

Galves, Charlotte Marie Chambelland. (1989) O objeto nulo no português brasileiro: percurso de uma pesquisa. Cadernos de Estudos Linguísticos 17, pp. 65-90.

Gavarró, Anna, Vicenç Torrens \& Ken Wexler (2010) Object Clitic Omission: Two Language Types. Language Acquisition 17 (4), pp. 192-219.

Genesee, Fred (1989) Early bilingual development: One language or two? Journal of child language 16 (1), pp. 161-179.

Grohmann, Kleanthes K, Eleni Theodorou, Natalia Pavlou, Evelina Leivada, Elena Papadopoulou \& Silvia Martínez-Ferreiro (2012) The development of object clitic placement in Cypriot Greek and the Romance connection. In Sadrine Ferré, Philippe Prévost, Laurice Tuller e Rasha Zebib (orgs.) Selected Proceedings of the Romance Turn IV. Newcastle: Cambridge Scholars Publishing, pp. 128-152.

Guasti, Maria Teresa (1993/1994) Verb syntax in Italian child grammar: Finite and nonfinite verbs. Language Acquisition 3:1, pp. 1-40.

Hamann, Cornelia \& Adriana Belletti (2006) Developmental Patterns in the Acquisition of Complement Clitic Pronouns - Comparing different acquisition modes with an emphasis on French, Revista di Grammatica Generativa 31, pp. 39-78.

Jakubowicz, Celia, Léa Nash, Catherine Rigaut, Christof-Loïc Gerard (1998) Determiners and Clitic Pronouns in French-Speaking Children with SLI. Language Acquisition 7 (2), pp. 113-160.

Kupisch, T., \& Rothman, J. (2018). Terminology matters! Why difference is not incompleteness and how early child bilinguals are heritage speakers. International Journal of Bilingualism, 22(5), pp. 564-582. 
Leivada, Evelina, Paraskevi Mavroudi \& Anna Epistithiou (2010) Metalanguage or bidialectism? acquisition of clitic placement by Hellenic Greeks, Greek Cypriots and Binationals in the Diglossic Context of Cyprus. ExLing, pp. 97-100.

Lopes, Ruth \& Sónia Cyrino (2005) Evidence for a cue-based theory of language change and language acquisition -the null object in Brazilian Portuguese. In Twan Geerts Twan e Haike Jacobs (orgs.) Romance Languages and Linguistic Theory. Amesterdam: John Benjamins, pp. 343-359.

Marinis, Theodoros (2000) The acquisition of clitic objects in Modern Greek: Single clitics, clitic doubling, clitic left dislocation. ZAS Papers in Linguistics 15, pp. 259-281.

Martins, Ana Maria (2013) A posição dos pronomes pessoais clíticos. In Eduardo Paiva Raposo, Maria Fernanda Bacelar do Nascimento, Maria Antónia Mota, Luísa Segura e Amália Mendes (orgs.) Gramática do Português. Lisboa: Fundação Calouste Gulbenkian, pp. 2231-2302.

Meisel, Jürgen (1989) Early differentiation of languages in bilingual children. In Kenneth Hyltenstam e Loraine Obler (orgs.) Bilingualism across the lifespan: Aspects of acquisition, maturity, and loss. Cambridge, UK: Cambridge University Press, pp. 13-40.

Meisel, Jürgen (2004) The bilingual child. In Tej K. Bhatia e William C. Ritchie (orgs.) The handbook of bilingualism. Blackwell Publishing, pp. 91-113.

Meisel, Jürgen (2008) Child second language acquisition or successive first language acquisition? Current trends in child second language acquisition, pp. 55-80.

Montrul, Silvina (2008). Incomplete acquisition in bilingualism: Re-examining the age factor (Vol. 39). John Benjamins Publishing.

Müller, Natacsha \& Aafke Hulk (2001) Crosslinguistic influence in bilingual language acquisition: Italian and French as recipient languages. Bilingualism: Language and Cognition, 4(1), pp. 1-21.

Nardelli, Marina (2015) Omissão de pronomes clíticos em crianças bilingues português europeu e espanhol ibérico. Dissertação de Mestrado, Universidade Nova de Lisboa.

Nardelli, Marina \& Maria Lobo (2017) Omissão de clíticos na aquisição bilingue português-espanhol. Revista da Associação Portuguesa de Linguística, 3, pp. 241-263.

Nardelli, Marina \& Maria Lobo (2018) Clitic omission in bilingual Portuguese-Spanish acquisition. In Anna Gavarró (org.) On the Acquisition of the Syntax of Romance. Amsterdam: John Benjamins, pp. 119-145.

Paradis, Johanne \& Fred Genesee (1996) Syntactic acquisition in bilingual children: Autonomous or interdependent? Studies in second language acquisition 18(1), pp. 1-25.

Paradis, Johanne, Martha Crago, Fred Genesee \& Mabel Rice (2003) Bilingual children with specific language impairment: How do they compare with their monolingual peers? Journal of Speech, Language and Hearing Research, 46, pp. 1-15.

Pérez-Leroux, Ana Teresa, Mihaela Pirvulescu \& Yves Roberge (2008) Null objects in child language: Syntax and the lexicon. Lingua 118 (3), pp. 370-398.

Petinou, Kakia \& Arhonto Terzi (2002) Clitic misplacement among developing children and children with specific language impairment and the status of Infl heads. Language Acquisition 10 (1), pp. 1-28.

Pirvulescu, Mihaela, Ana-Teresa Pérez-Leroux, Yves Roberge, Nelleke Strik \& Danielle Thomas (2014) Bilingual effects: Exploring object omission in pronominal languages. Bilingualism: Language and Cognition 17(3), pp. 495-510.

Raposo, Eduardo Paiva (1986) On the Null Object Construction in European Portuguese. In Osvaldo Jaeggli e Carmen Silva-Corvalán (orgs.) Studies in Romance Linguistics. Dordrecht: Foris, pp. 373-390.

Raposo, Eduardo Paiva (1989) Prepositional infinitival constructions in European Portuguese. In Osvaldo Jaeggli e Kenneth Safir (orgs.) The Null Subject Parameter. Dordrecht: Kluwer, pp. 277-305.

Raposo, Eduardo Paiva (2004) Objectos nulos e CLLD: uma teoria unificada. Revista da ABRALIN 3 (1/2), pp. 41-73. 
Rinke, Esther \& Cristina Flores (2014) Morphosyntactic knowledge of clitics by Portuguese heritage bilinguals. Bilingualism: Language and Cognition 17 (4), pp. 681-699.

Rinke, Esther, Cristina Flores \& Aldona Sopata (2019) Heritage Portuguese and Heritage Polish in contact with German. More evidence on the production of objects. Languages, 4(3), 53.

Rinke, Esther, Cristina Flores \& Pilar Barbosa (2018) Null objects in the spontaneous speech of monolingual and bilingual speakers of European Portuguese. Probus 30 (1), pp. 93-119.

Rothman, Jason (2009) Understanding the nature and outcomes of early bilingualism: Romance languages as heritage languages. International Journal of Bilingualism, 13(2), pp. 155-163.

Rothman, Jason \& Michael Iverson (2013) Islands and objects in L2 Spanish: Do You Know the Learners Who Drop_? Studies in Second Language Acquisition 35 (4), pp. 598-618.

Santos, Maria de Fátima Nascimento (2002) Os Pronomes Pessoais Átonos no Português Europeu. Descrição de Problemas que Ocorrem no $3^{\circ}$ ciclo e Proposta de Actividades Didáticas. Dissertação de Mestrado, Universidade de Lisboa.

Silva, Carolina (2008) Assimetrias na aquisição de clíticos diferenciados em português europeu. Dissertação de Mestrado, Universidade Nova de Lisboa.

Silva, Carolina (2009) Assimetrias na aquisição de diferentes tipos de clíticos em português europeu. Textos Seleccionados do XXIV Encontro Nacional da Associação Portuguesa de Linguística. Lisboa: APL, pp. 527-541.

Thomas, Enlli Môn, Nia Williams, Llinos Angharad Jones, Susi Davies \& Hanna Binks (2014) Acquiring complex structures under minority language conditions: Bilingual acquisition of plural morphology in Welsh. Bilingualism: Language and Cognition, 17 (3), pp. 478-494.

Tsakali, Vina \& Kenneth Wexler (2004) Why children omit clitics in some languages but not in others: new evidence from Greek. In Jacqueline van Kampen e Sergio Baauw (orgs.) Proceedings of GALA 2003. Utrecht: LOT, pp. 493-504.

Tuller, Laurice (2000) Aspects de la morphosyntaxe du français des sourds. Recherches linguistiques de Vincennes 29, pp. 43-156.

Unsworth, Sharon. (2005) Child L2, Adult L2, Child L1: Differences and Similarities. A study on the acquisition of direct object scrambling in Dutch. Dissertação de Doutoramento, LOT.

Varlokosta, Spyridoula, João Costa, Naama Friedmann, Anna Gavarró, Kleanthes K. Grohmann, ... \& Kazuko Yatsushiro (2015) A Cross-Linguistic Study of the Acquisition of Clitic and Pronoun Production. Language Acquisition 23 (1), pp. 1-26.

Vieira, Sílvia (2008) Colocação pronominal. In Sílvia Rodrigues Vieira e Sílvia Figueiredo Brandão (orgs.) Ensino de gramática. Descrição e uso. São Paulo: Editora Contexto, pp. 121-146.

Wexler, Kenneth, Anna Gavarró \& Vicent Torrens (2004) Feature checking and object clitic omission in child Catalan and Spanish. In Reineke Bok-Bennema, Bart Hollebrandse, Brigitte Kampers-Manhe \& Petra Sleeman (orgs.), Romance languages and linguistic theory 2002. Amsterdam: John Benjamins, pp. 25370 . 